\title{
Synthesis of Mono- and Dihydroxylated Furanoses, Pyranoses, and an Oxepanose for the Preparation of Natural Product Analogue Libraries.
}

\author{
Xiao Ming Yu, Huijong Han, and Brian S. J. Blagg*
}
Department of Medicinal Chemistry and The Center for Protein Structure and Function, The University of Kansas, 1251 Wescoe Hall Dr., Malott Hall 4070, Lawrence, KS 66045-7564

bblagg@ku.edu

\section{SUPPORTING INFORMATION}




\section{TABLE OF CONTENTS}

${ }^{1} \mathrm{H}$ NMR spectrum of 14

${ }^{13} \mathrm{C}$ NMR spectrum of 14

${ }^{1} \mathrm{H}$ NMR spectrum of 15

${ }^{13} \mathrm{C}$ NMR spectrum of 15

${ }^{1} \mathrm{H}$ NMR spectrum of 16

S5

${ }^{13} \mathrm{C}$ NMR spectrum of 16

${ }^{1} \mathrm{H}$ NMR spectrum of 19

S7

${ }^{13} \mathrm{C}$ NMR spectrum of 19

S8

${ }^{1} \mathrm{H}$ NMR spectrum of 20

${ }^{13} \mathrm{C}$ NMR spectrum of 20

$\mathrm{S} 10$

${ }^{1} \mathrm{H}$ NMR spectrum of 21

S11

${ }^{13} \mathrm{C}$ NMR spectrum of 21

$\mathrm{S} 12$

${ }^{1} \mathrm{H}$ NMR spectrum of 23

${ }^{13} \mathrm{C}$ NMR spectrum of 23

${ }^{1} \mathrm{H}$ NMR spectrum of 24

S15

${ }^{13} \mathrm{C}$ NMR spectrum of 24

S16

${ }^{1} \mathrm{H}$ NMR spectrum of 28

S17

${ }^{13} \mathrm{C}$ NMR spectrum of 28

${ }^{1} \mathrm{H}$ NMR spectrum of 29

${ }^{13} \mathrm{C}$ NMR spectrum of 29

S20

${ }^{1} \mathrm{H}$ NMR spectrum of 32

S21

${ }^{13} \mathrm{C}$ NMR spectrum of 32

${ }^{1} \mathrm{H}$ NMR spectrum of 33

${ }^{13} \mathrm{C}$ NMR spectrum of 33

S24

${ }^{1} \mathrm{H}$ NMR spectrum of 35

S25

${ }^{13} \mathrm{C}$ NMR spectrum of 35

S26

${ }^{1} \mathrm{H}$ NMR spectrum of 36

S27

${ }^{13} \mathrm{C}$ NMR spectrum of 36

${ }^{1} \mathrm{H}$ NMR spectrum of 39

S29

${ }^{13} \mathrm{C}$ NMR spectrum of 39

S30

${ }^{1} \mathrm{H}$ NMR spectrum of 40

S31

${ }^{13} \mathrm{C}$ NMR spectrum of 40

S32

${ }^{1} \mathrm{H}$ NMR spectrum of 41

S33

${ }^{13} \mathrm{C}$ NMR spectrum of 41

S34

${ }^{1} \mathrm{H}$ NMR spectrum of 43

S35

${ }^{13} \mathrm{C}$ NMR spectrum of 43

S36

${ }^{1} \mathrm{H}$ NMR spectrum of 44

S37

${ }^{13} \mathrm{C}$ NMR spectrum of 44

${ }^{1} \mathrm{H}$ NMR spectrum of 47

S39

${ }^{13} \mathrm{C}$ NMR spectrum of 47

S40

${ }^{1} \mathrm{H}$ NMR spectrum of 48

S41

${ }^{13} \mathrm{C}$ NMR spectrum of 48 


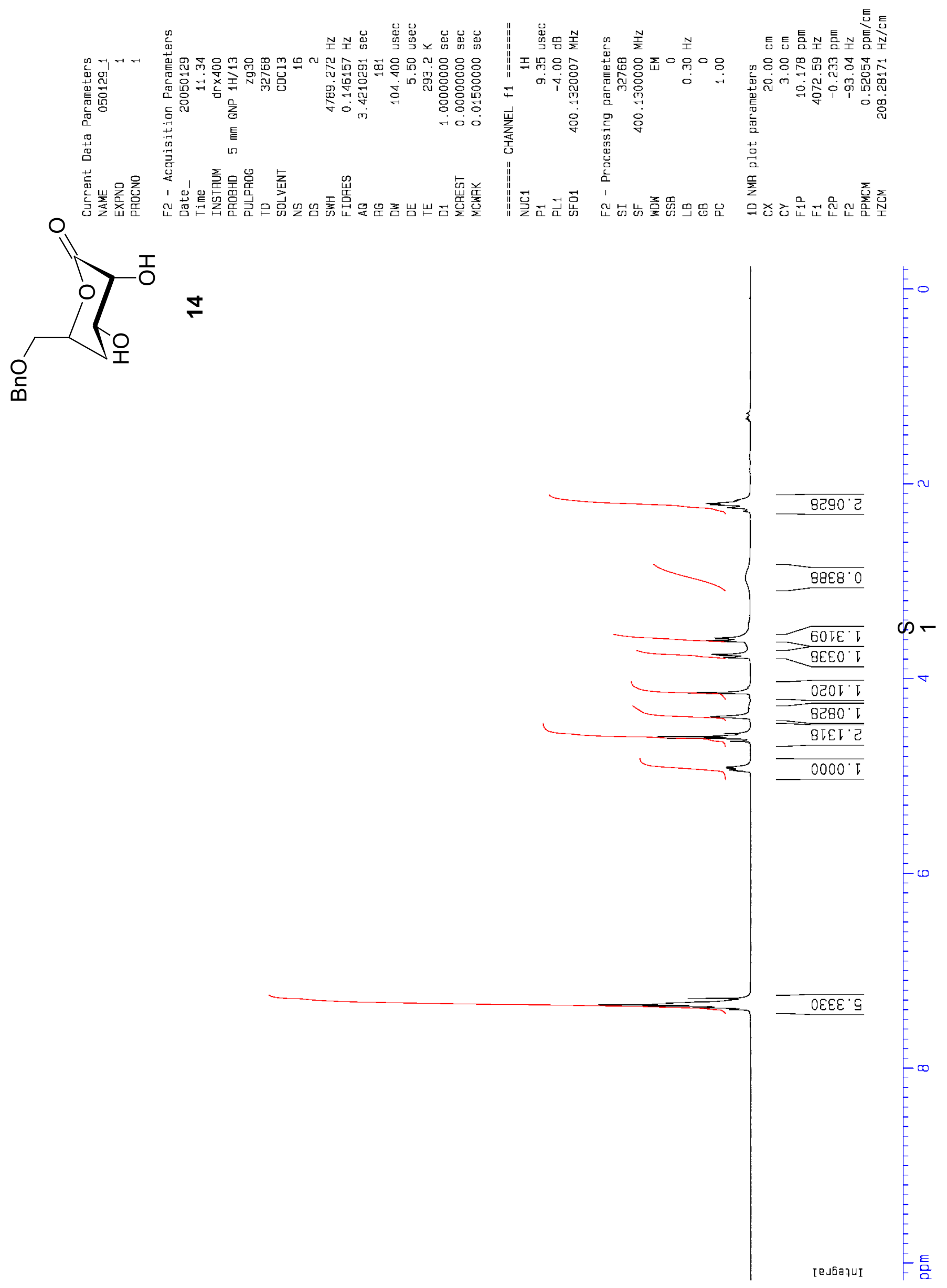




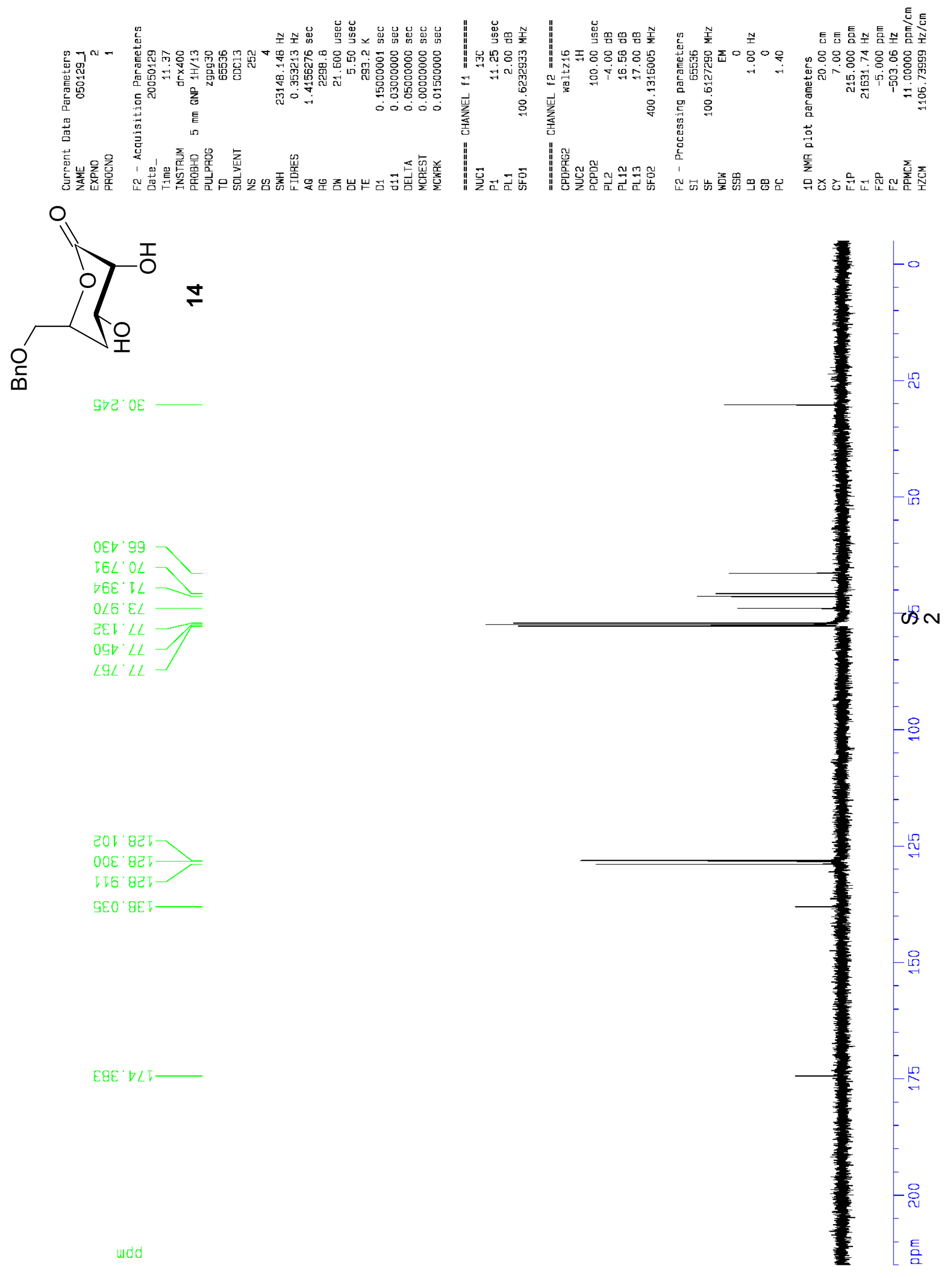



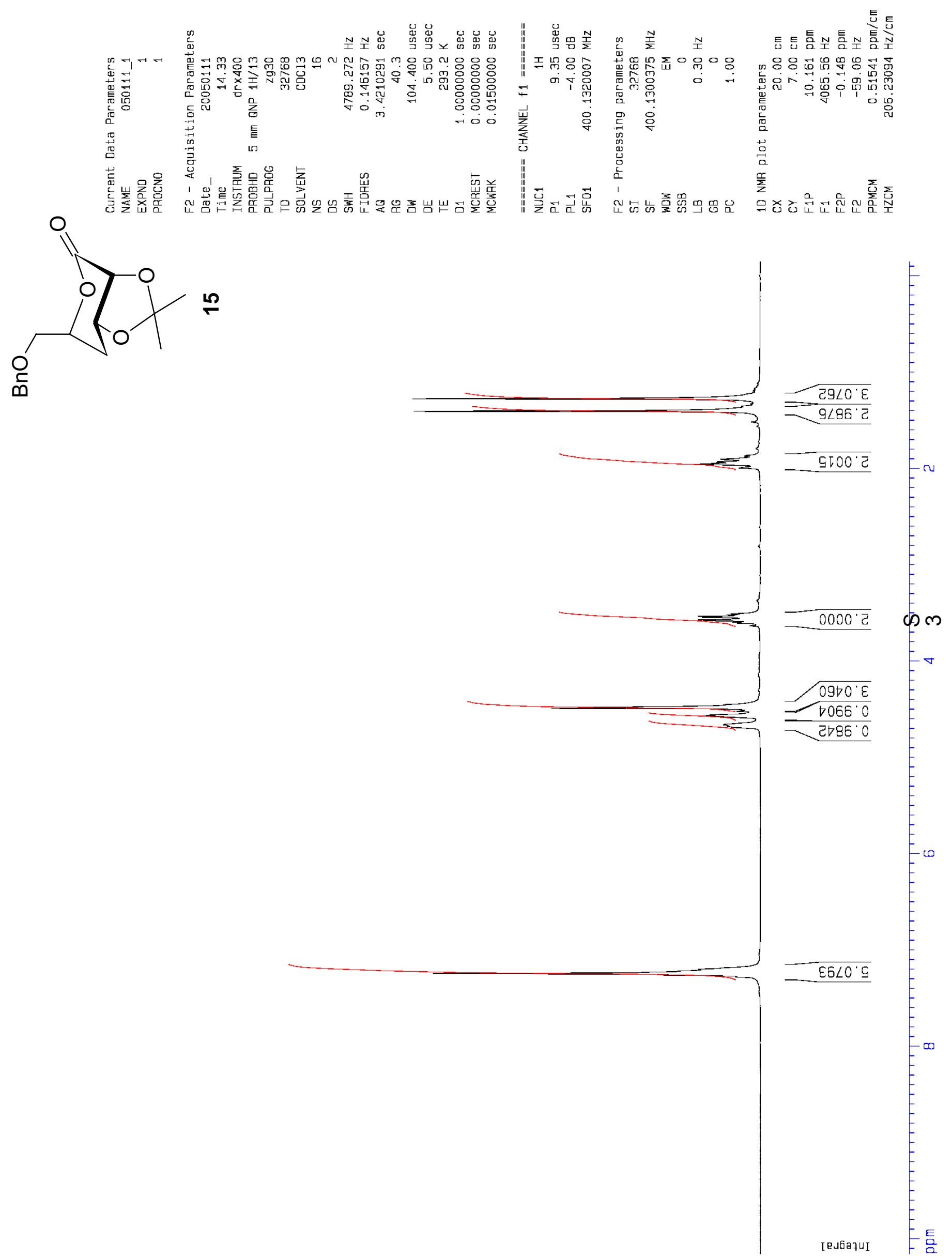


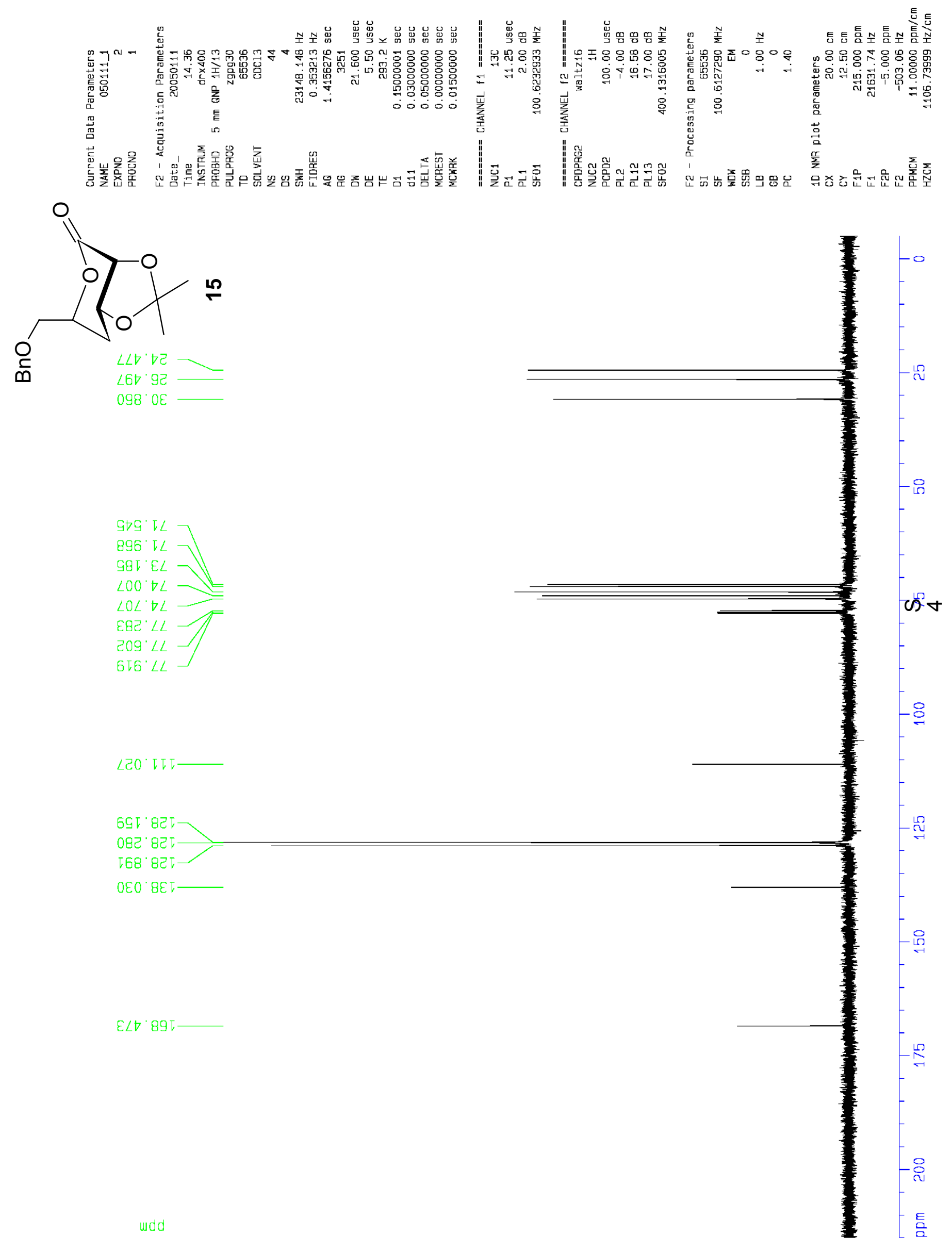




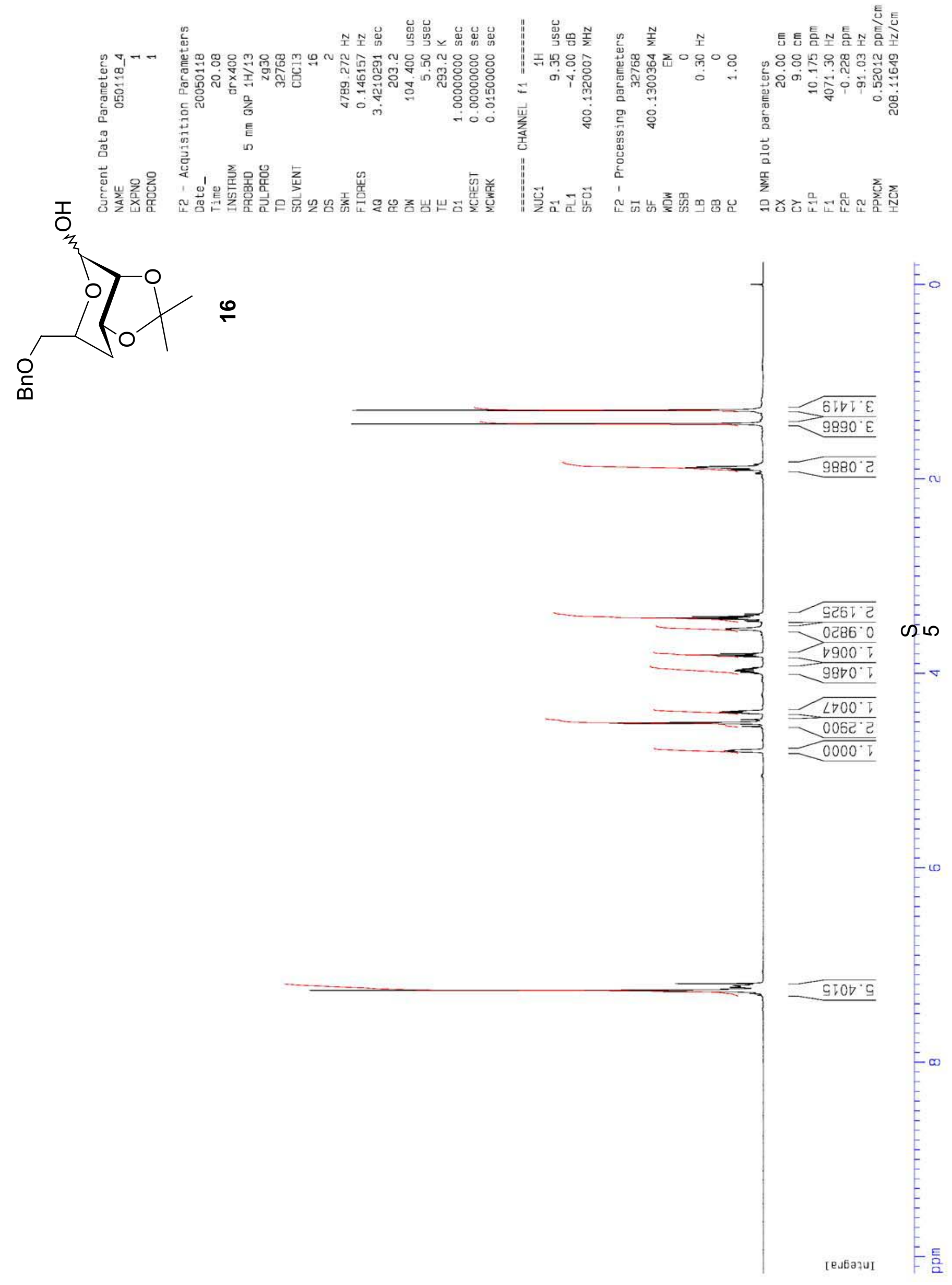



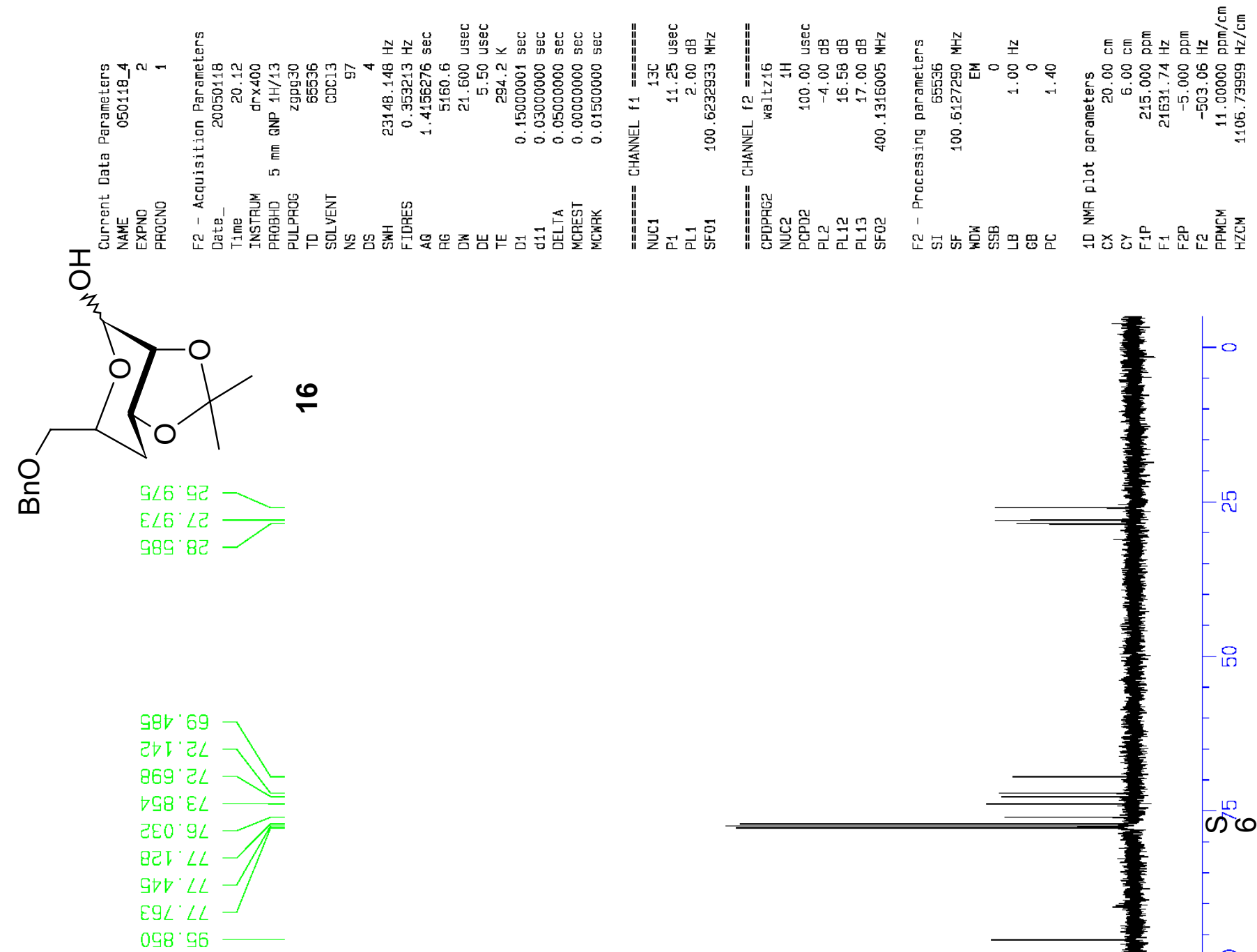

$079^{\circ} 60 t$

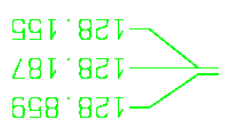

$\varepsilon 0 己 \cdot 8 \varepsilon \tau$

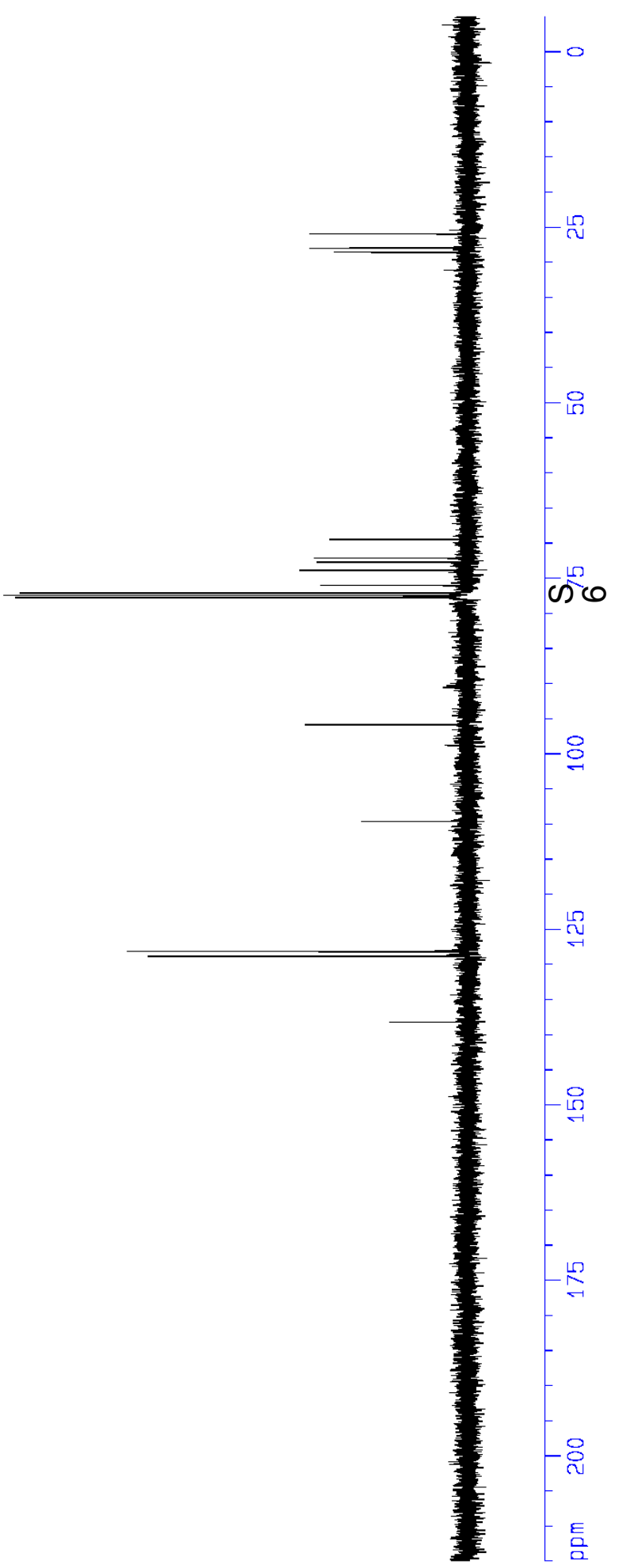



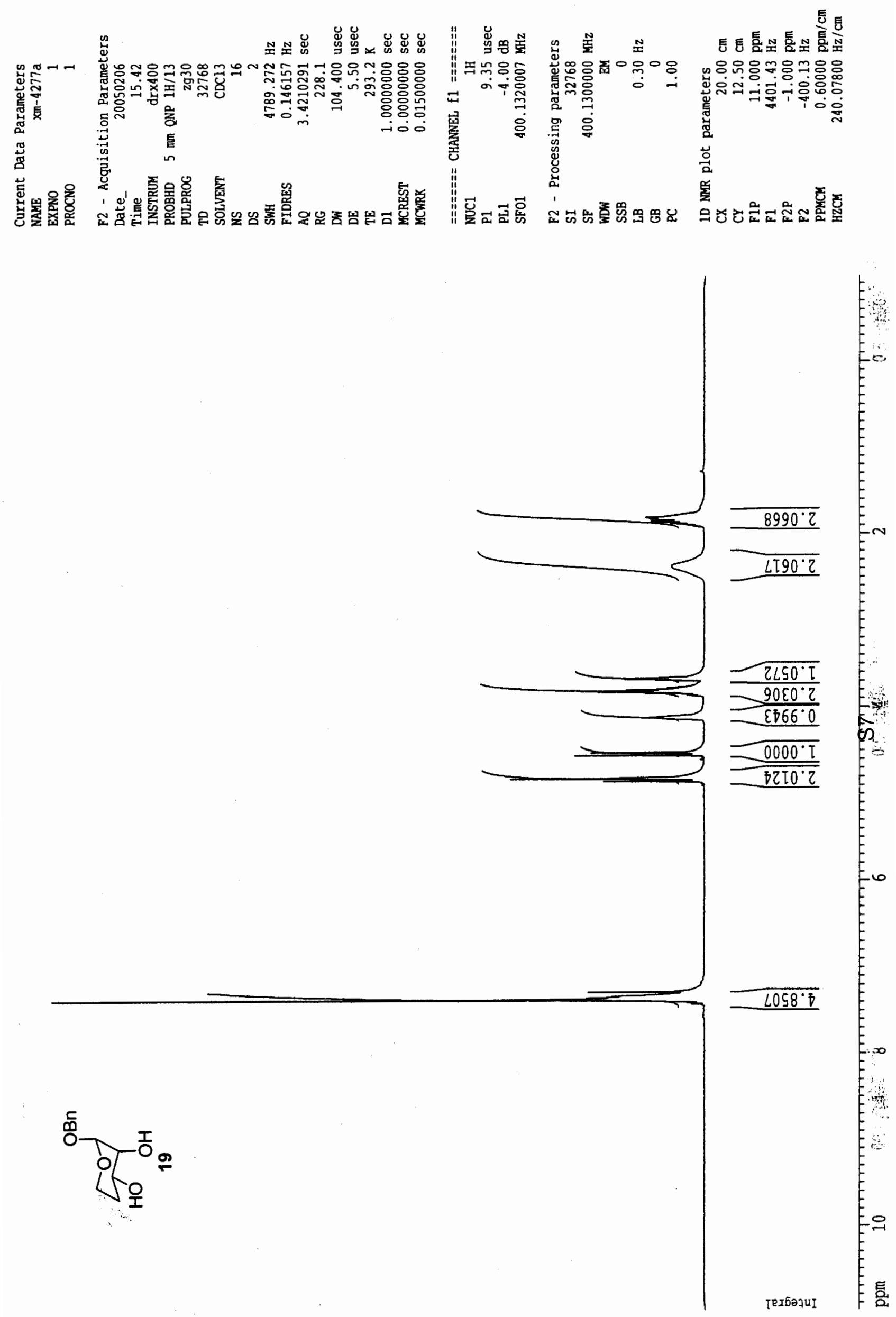


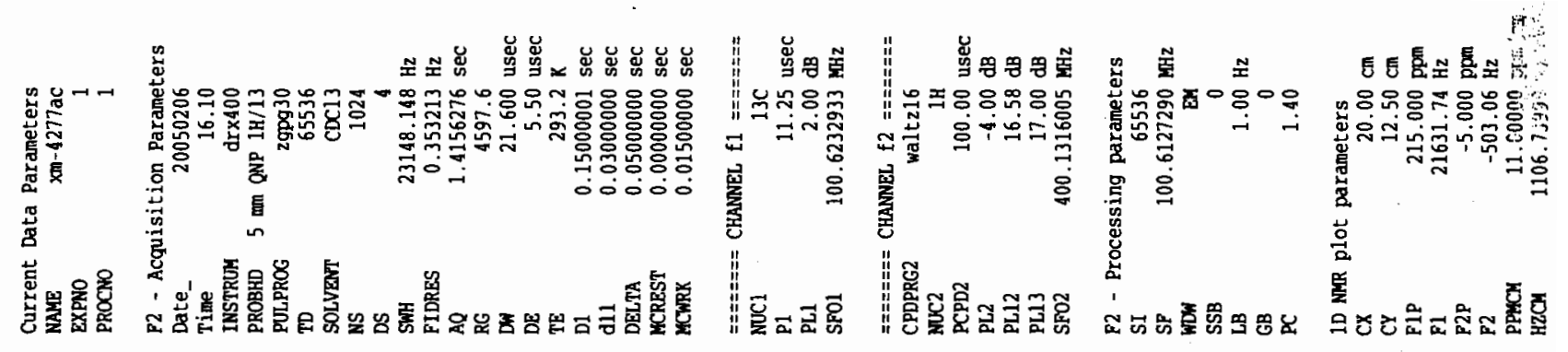

$6 L \varepsilon^{\circ} \circ \varepsilon$

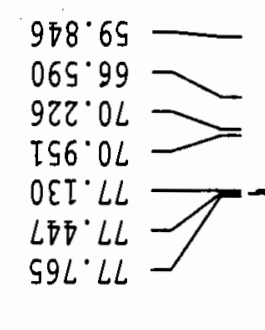

$016.66-$

ธLE.8ZT

0ZБ.8ZT

$9\{6.82$ T

L69 $L E T$

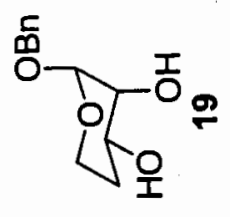

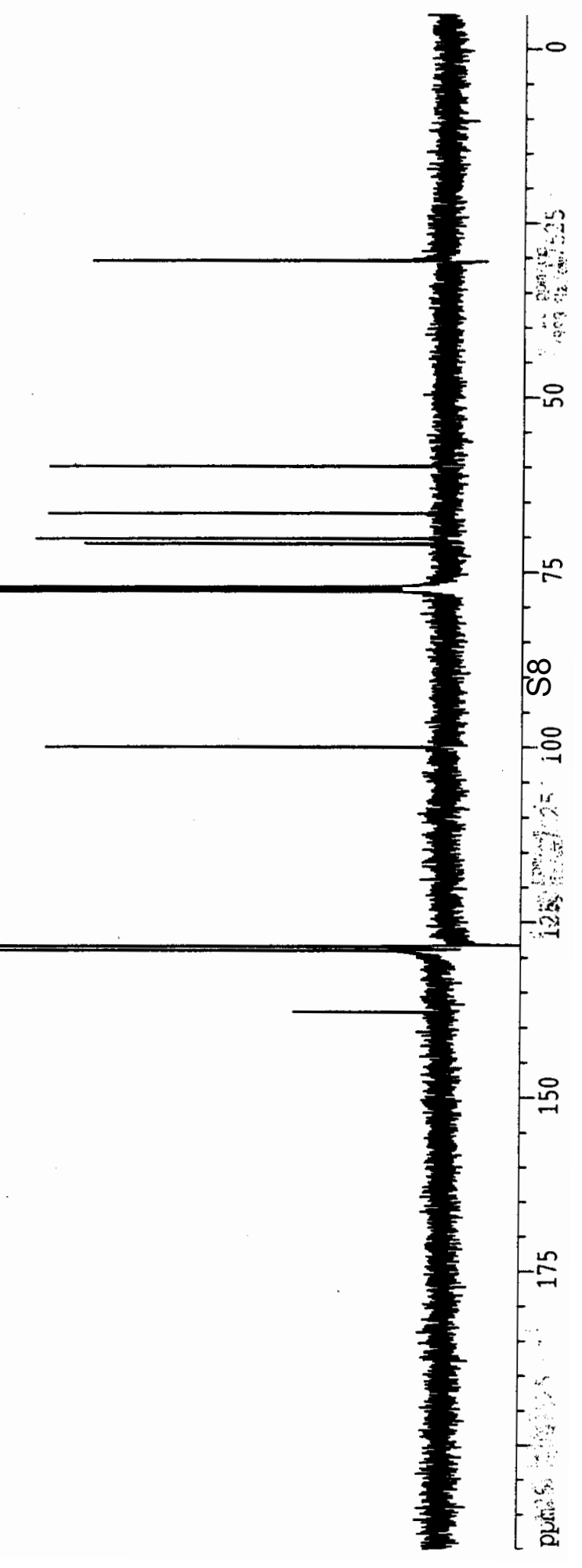



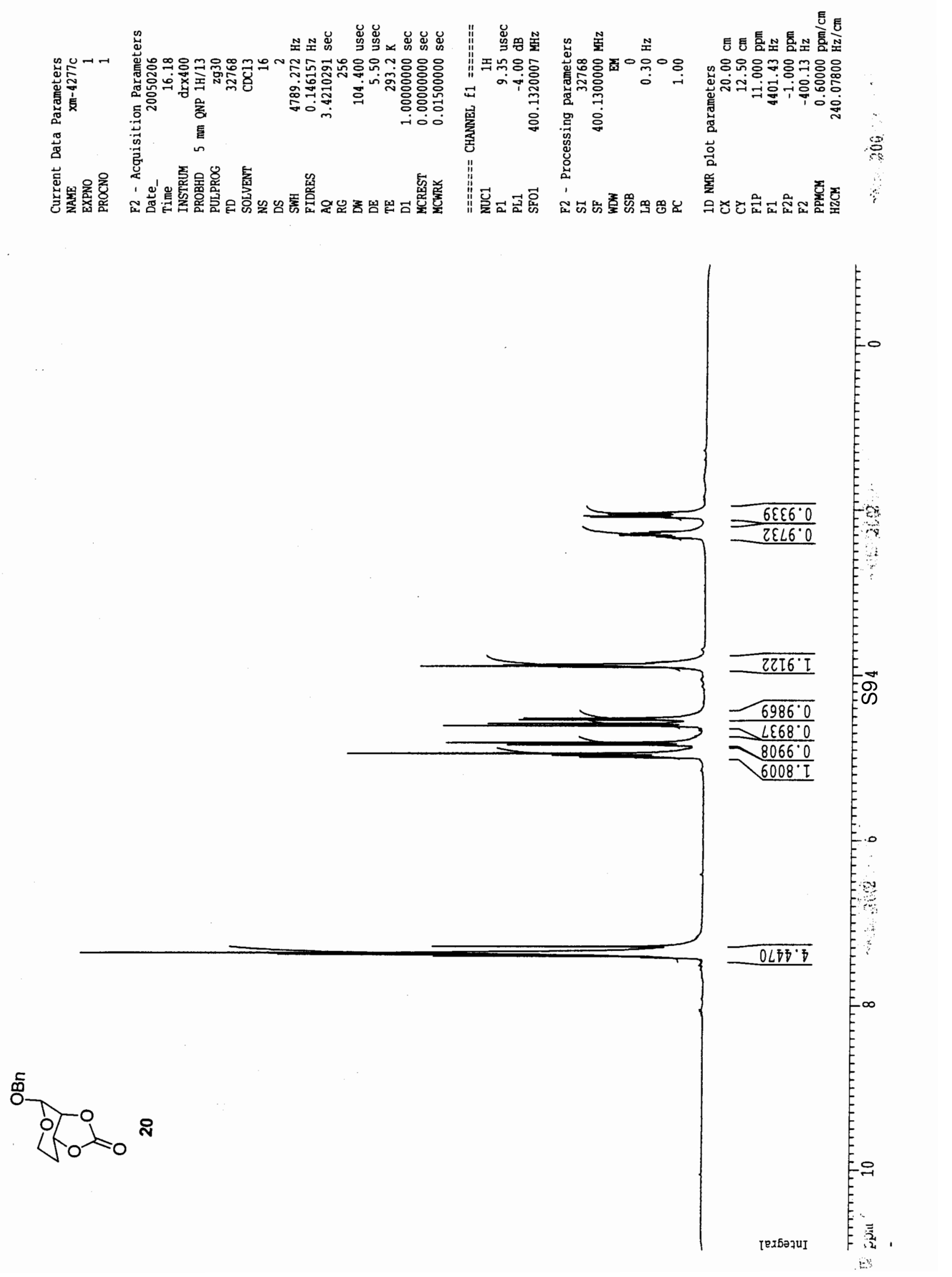


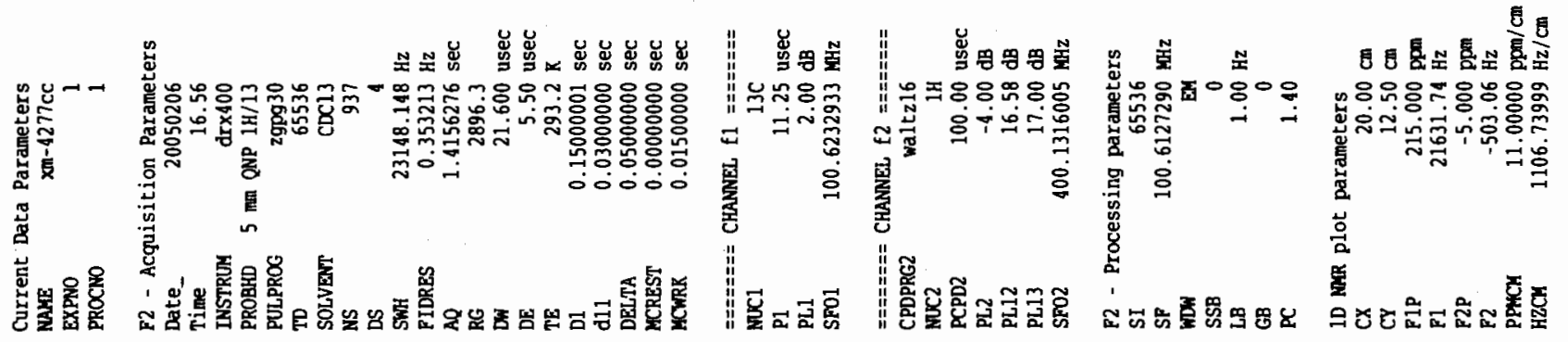

$8 L I^{\circ} \subseteq Z$

$000^{\circ} \mathrm{LS}$

$8 \angle D^{\circ} O L$

T69. ZL

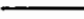

8ZI'LL

$9 \pi D^{\circ} \mathrm{LL}$

$\varepsilon 9 L^{\circ} L L$

$666^{\circ} 56$

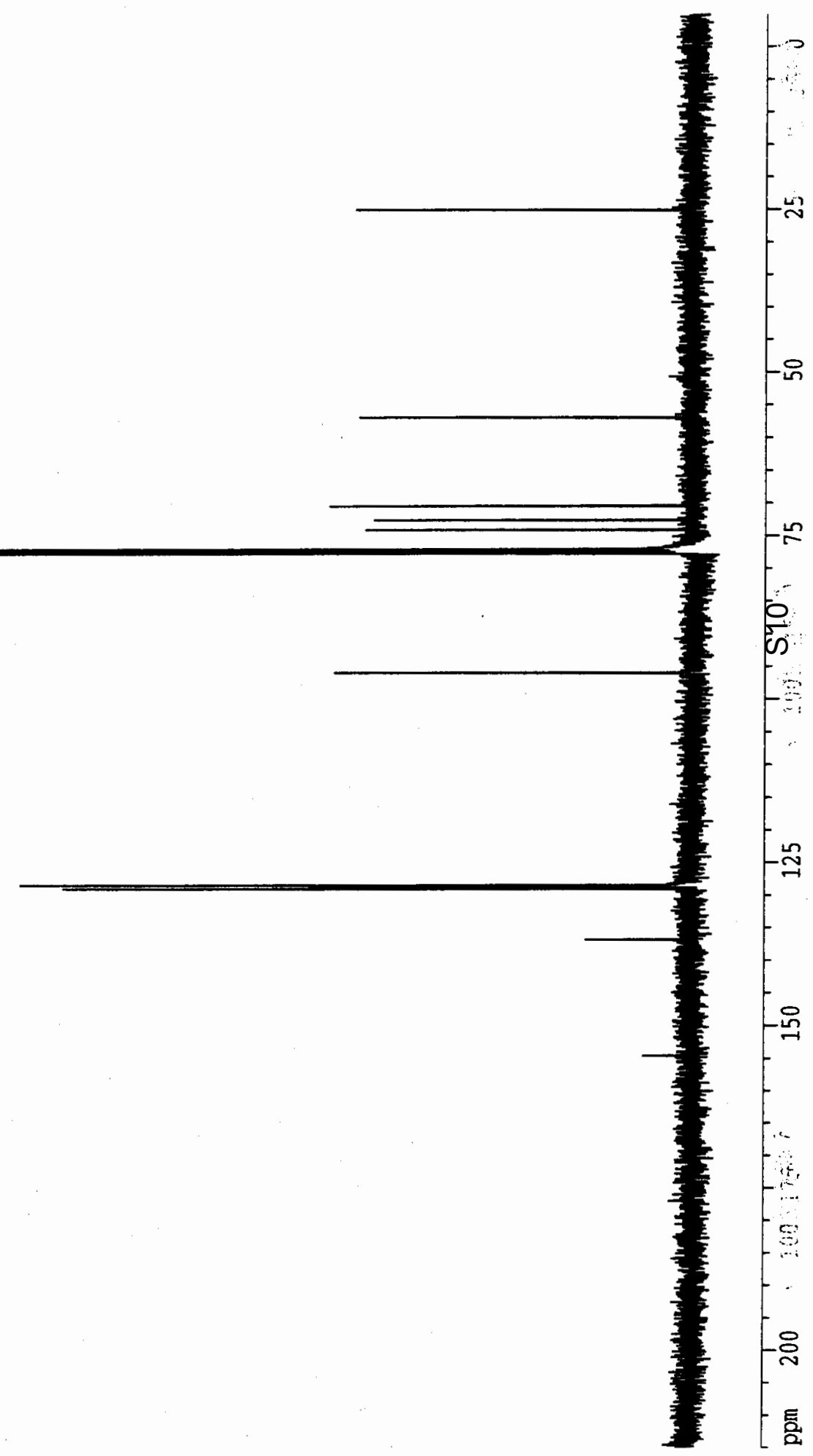

$\angle Z 5^{\circ} 8 Z I$
$989^{\circ} 8 Z I$

$250^{\circ} 6 \mathrm{ZI}$

จ88.9 9 I

O95'唒—

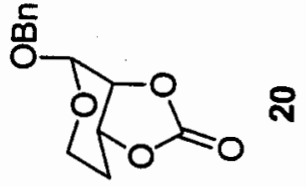



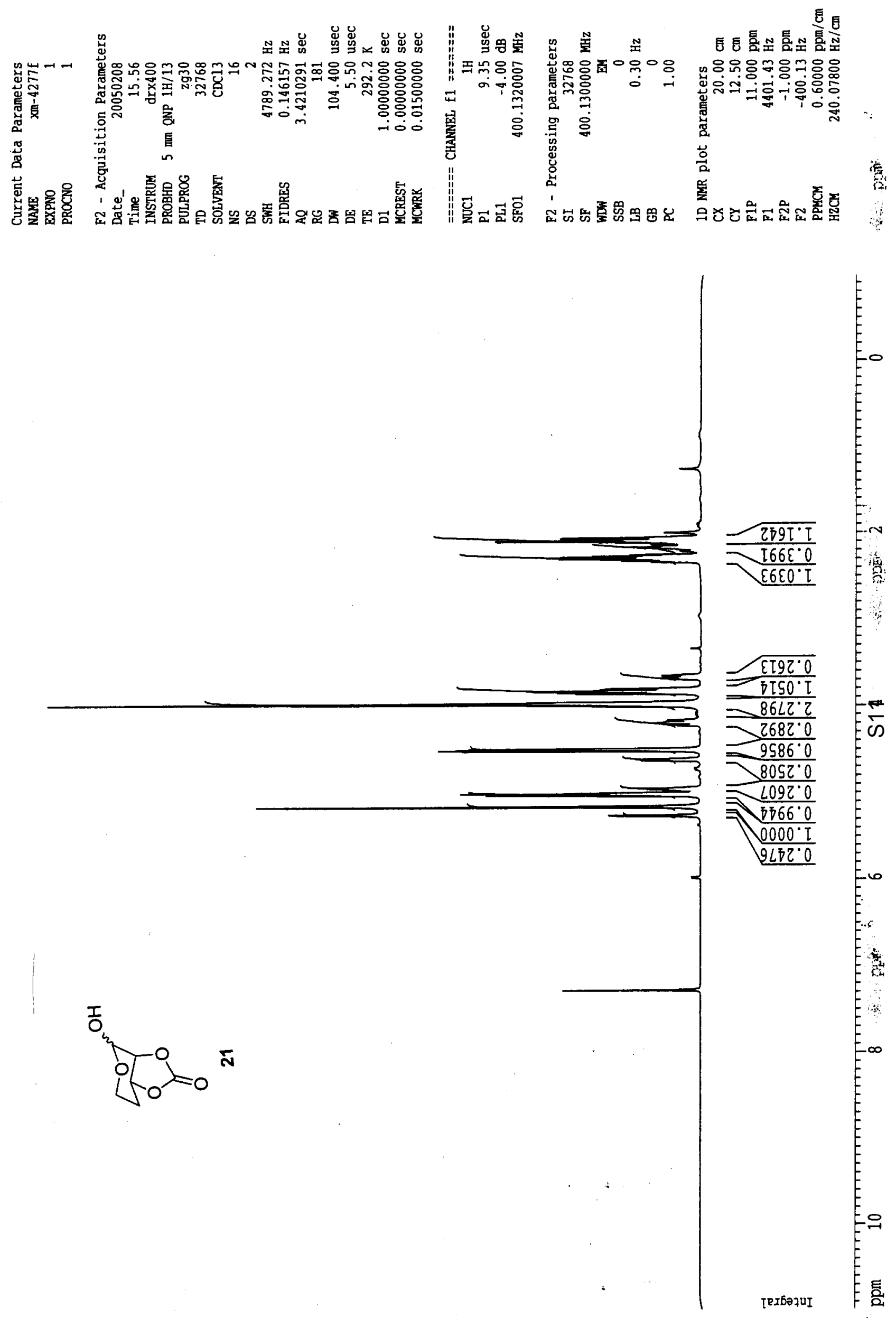

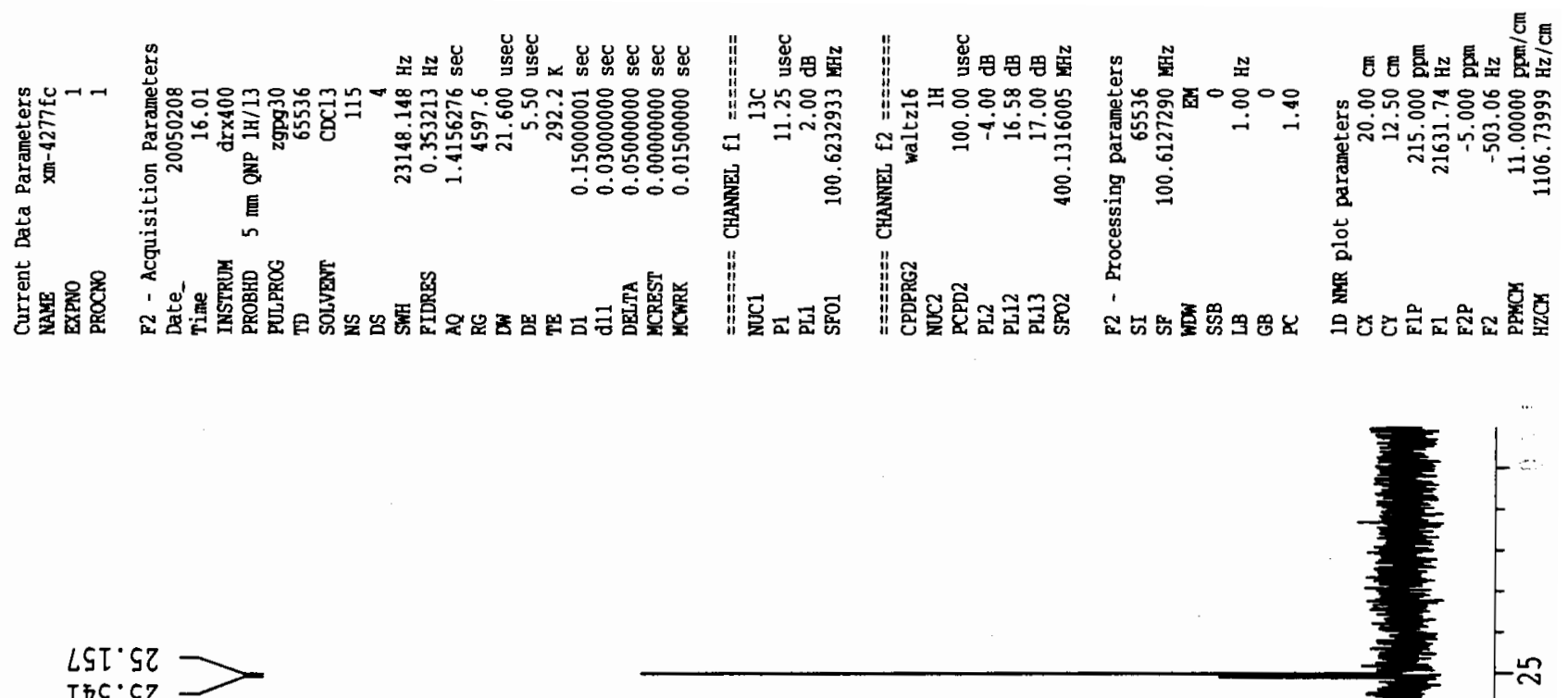

$80 D^{\circ} 5 S=$
$829^{\circ} \mathrm{LS}=$

$\varepsilon 99^{\circ} \mathrm{ZL}$

$8 \varepsilon \varsigma^{\circ} \varepsilon$

$62 \varepsilon^{\circ} \curvearrowleft L$

$\angle 66^{\circ} D L$

$8 \pi T^{\circ} L L$

$990^{\circ} \mathrm{LL}$

$\varepsilon 8 L^{\circ} \mathrm{LL}$

9 โ8.68

$9 L \varepsilon^{\prime} 26$

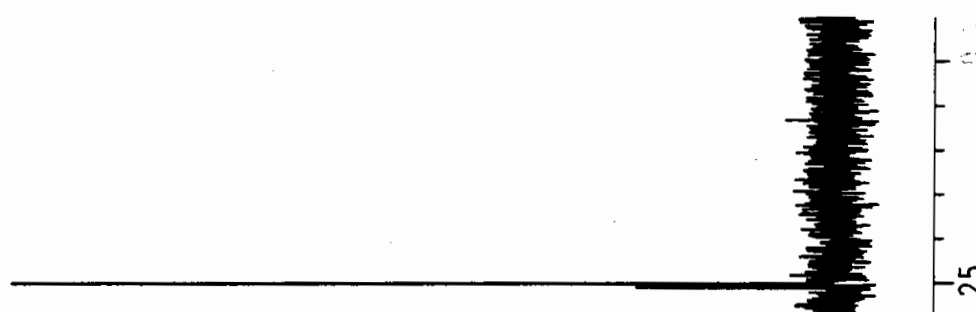

9I0. SST-<smiles>[CH2-][C@@H]1OC2CCC1OC(=O)O2</smiles>
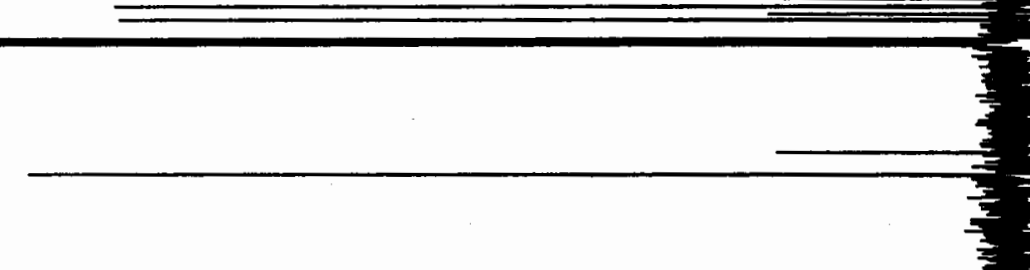

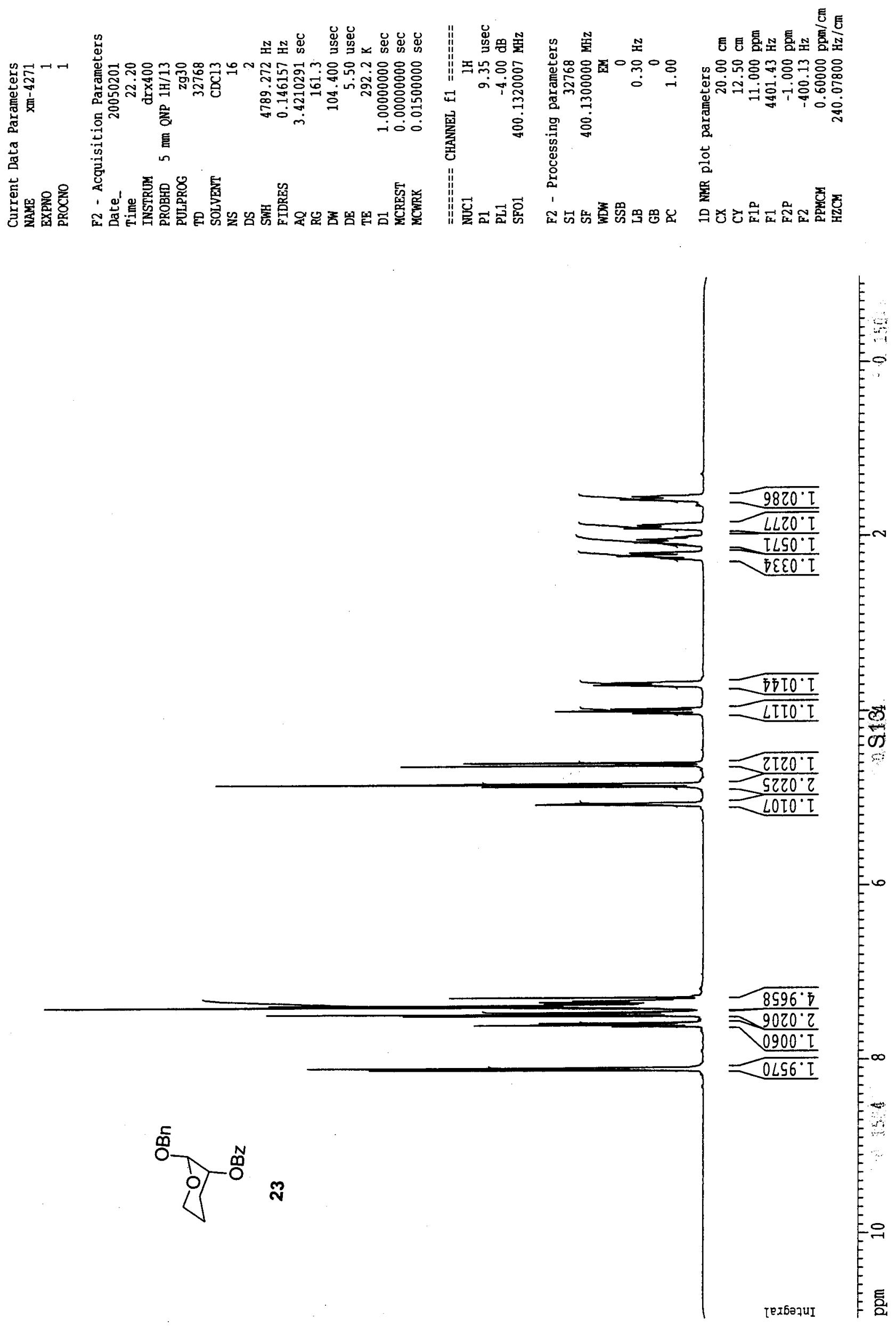

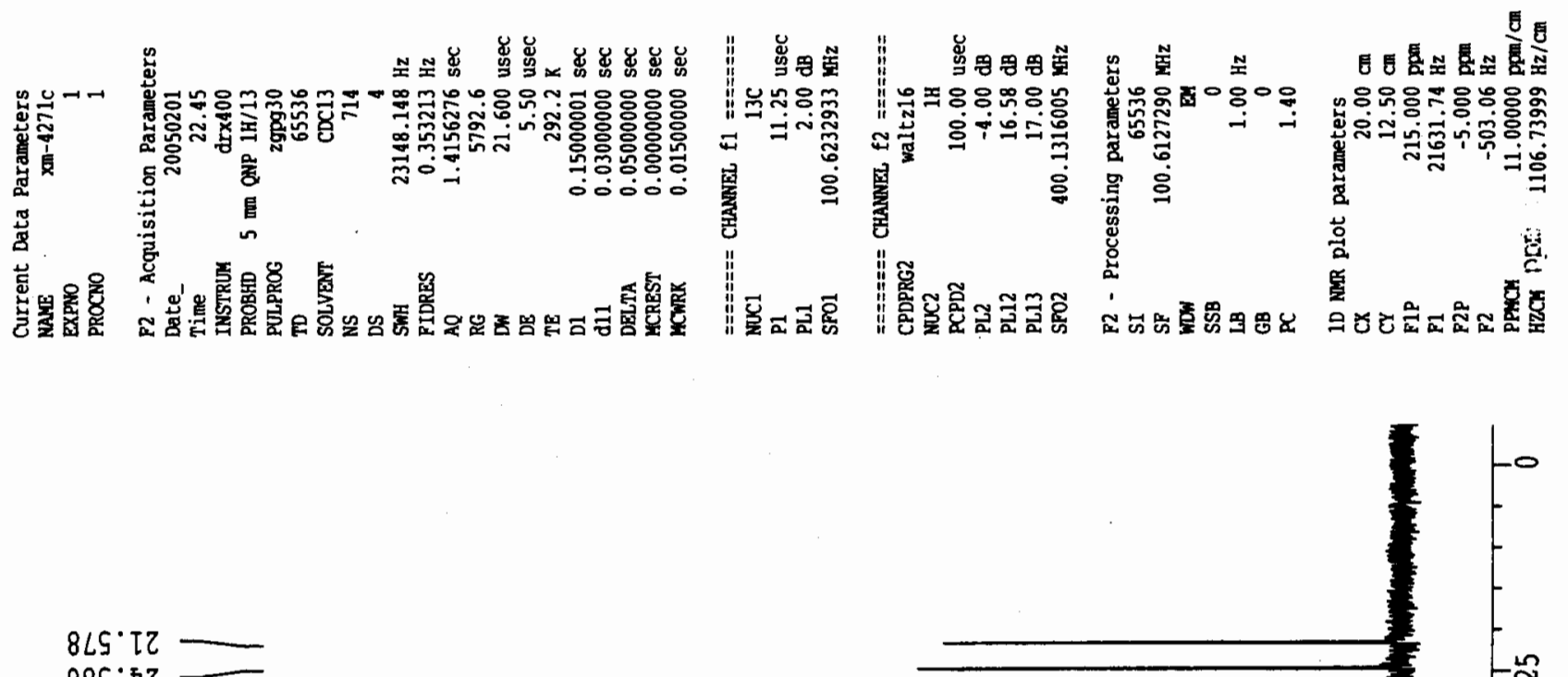

$985^{\circ} \nabla 2$

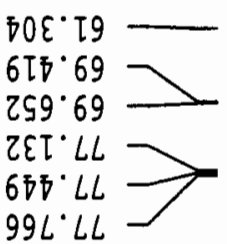

$\nabla \varepsilon \varepsilon^{\circ}\llcorner 6-$

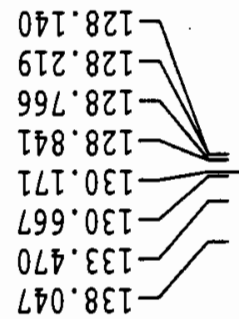

TรT'99T
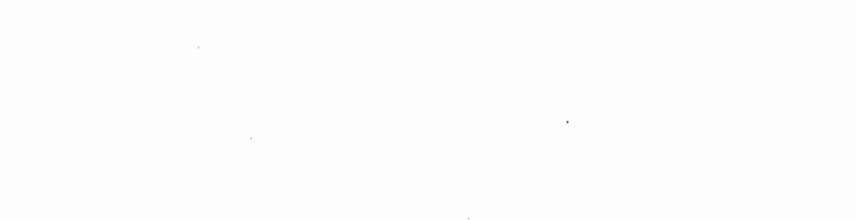

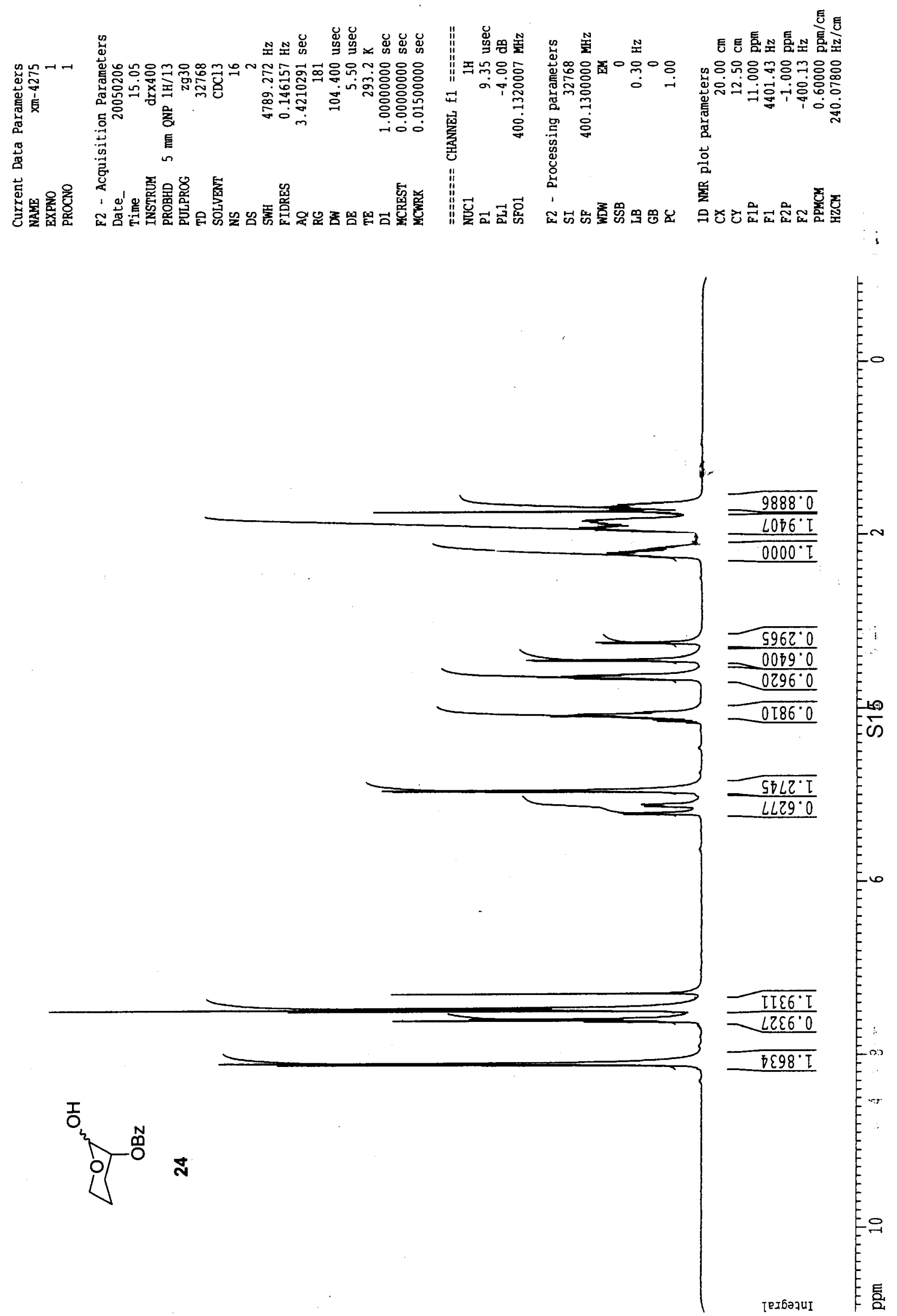

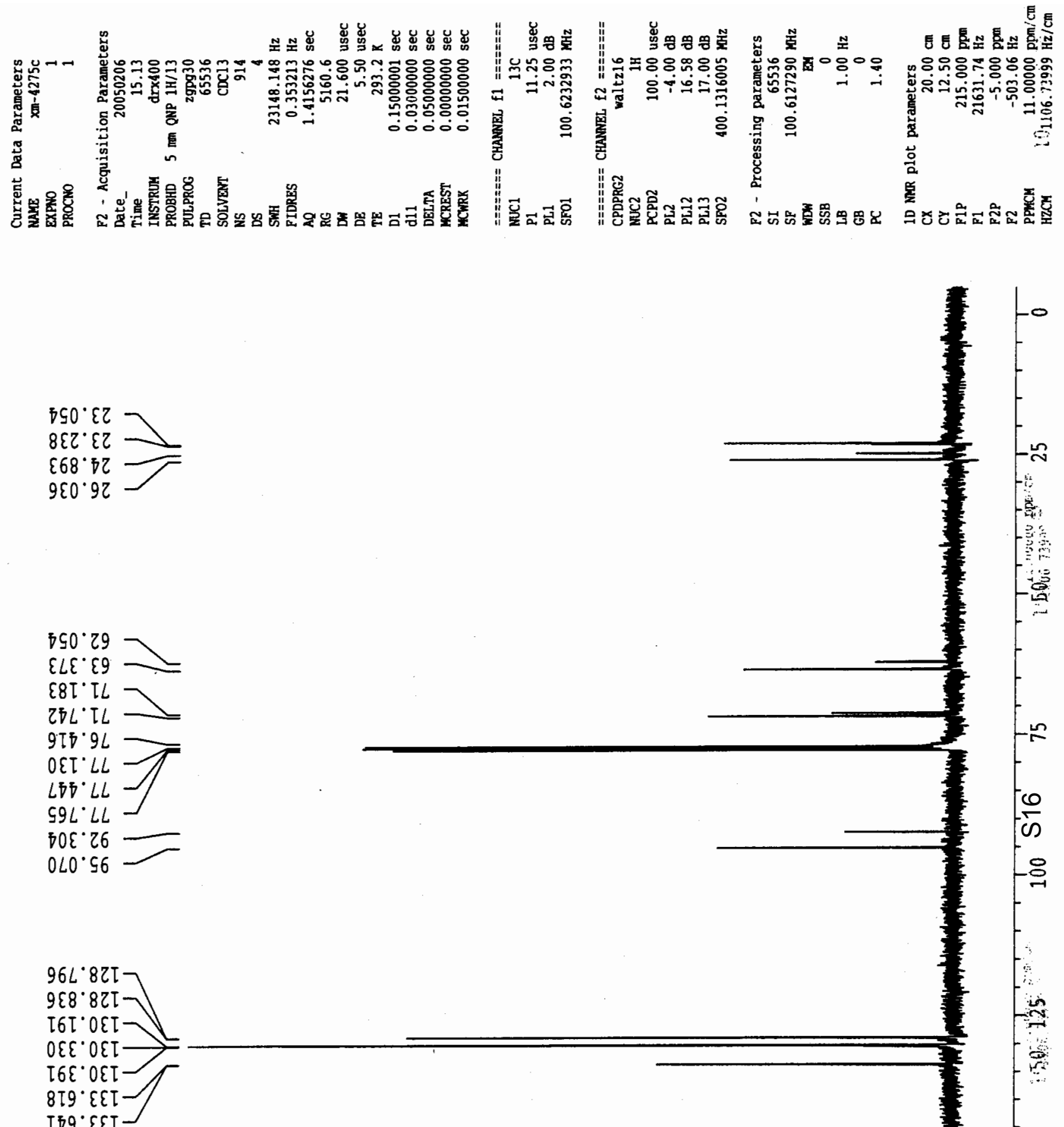

โธด हEโ
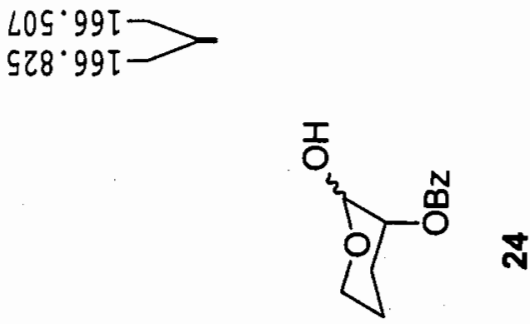

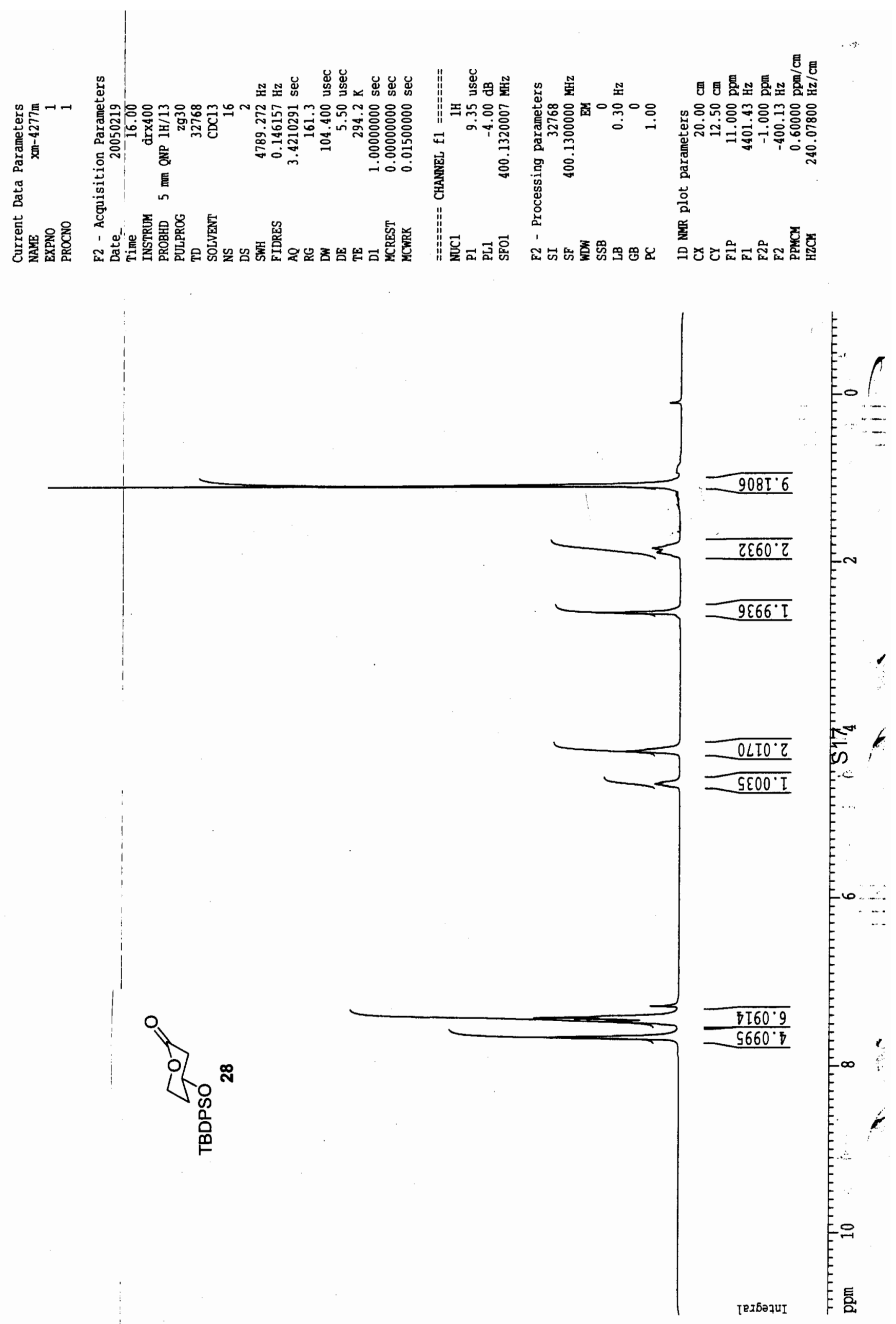

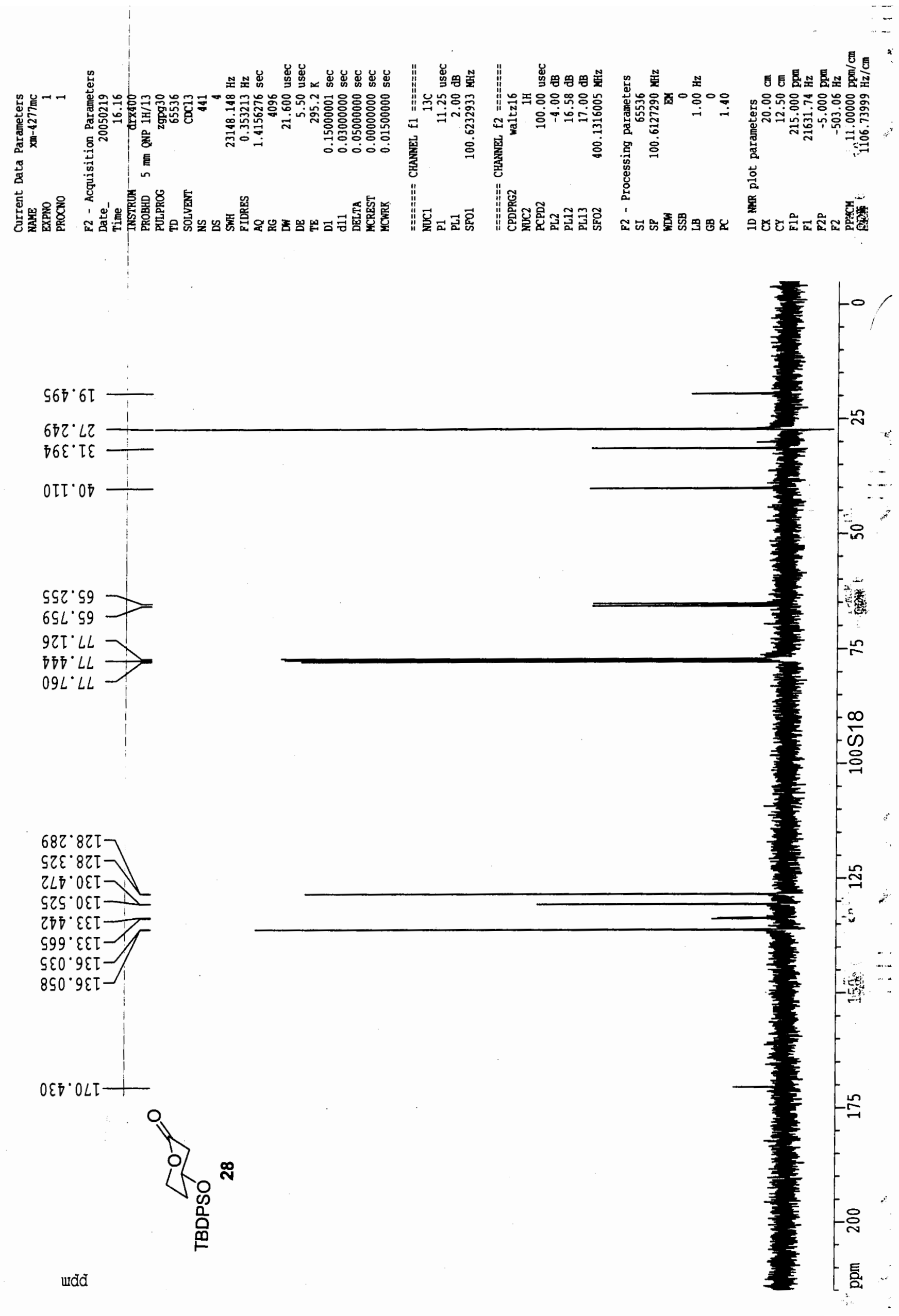

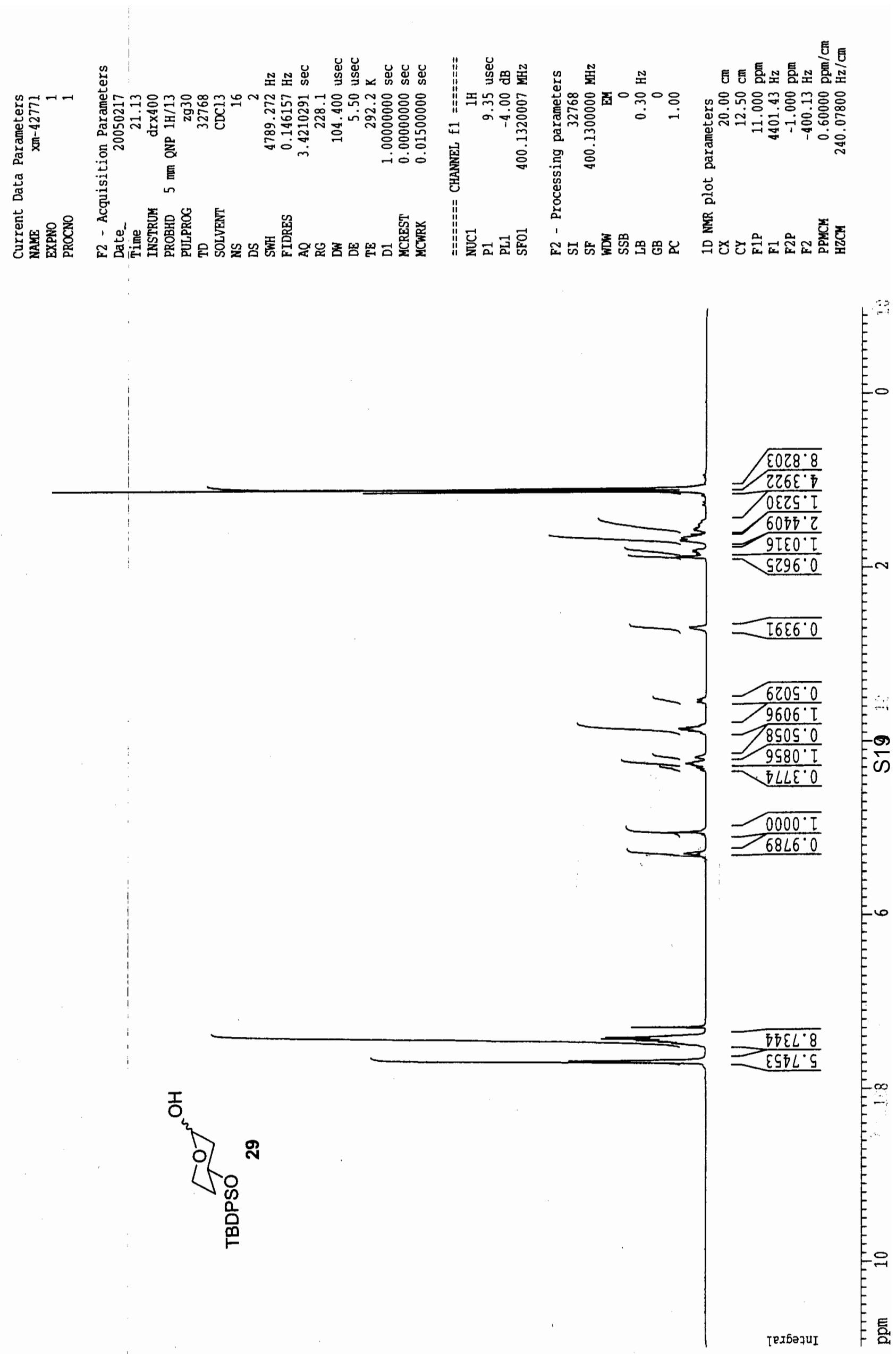

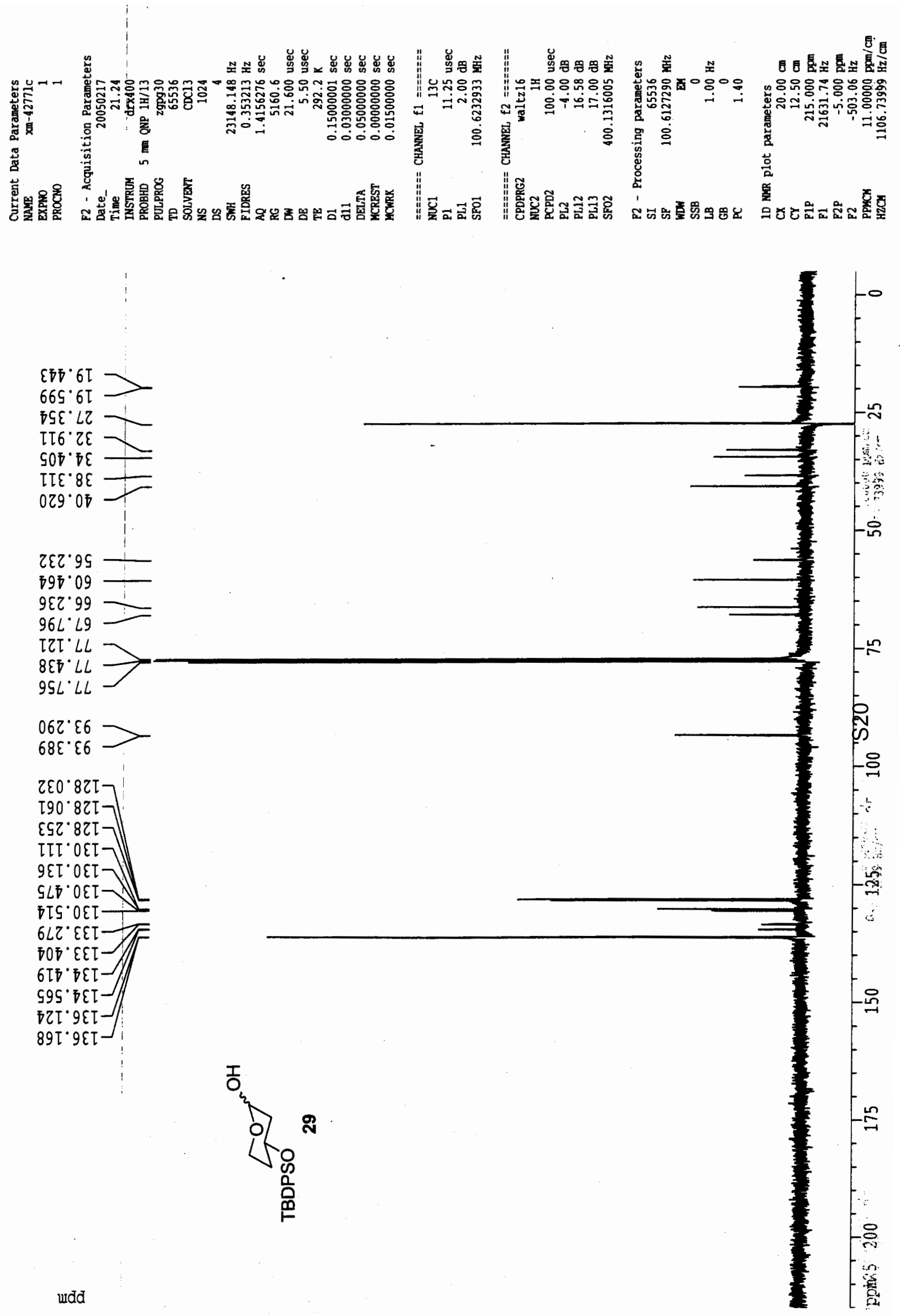

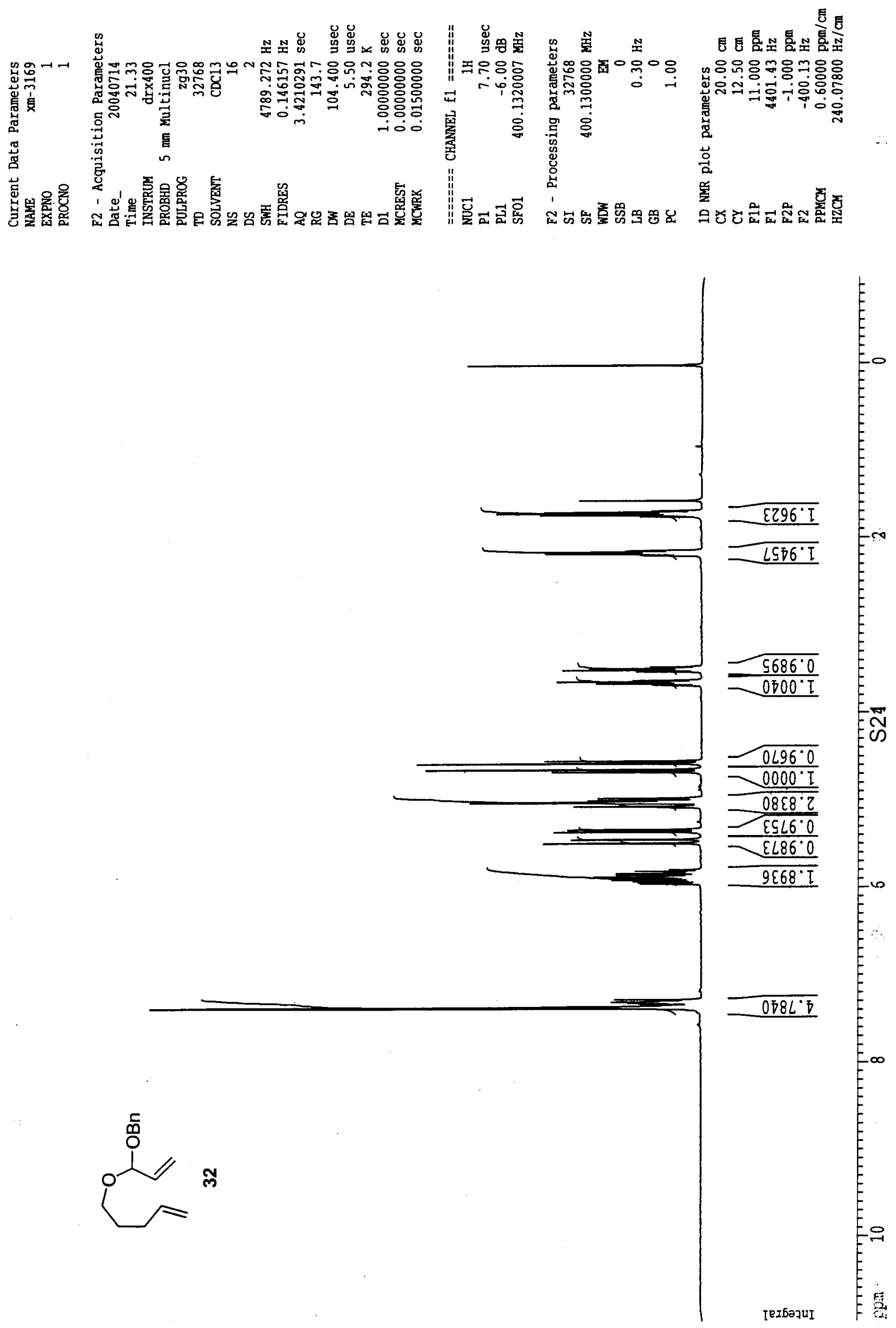

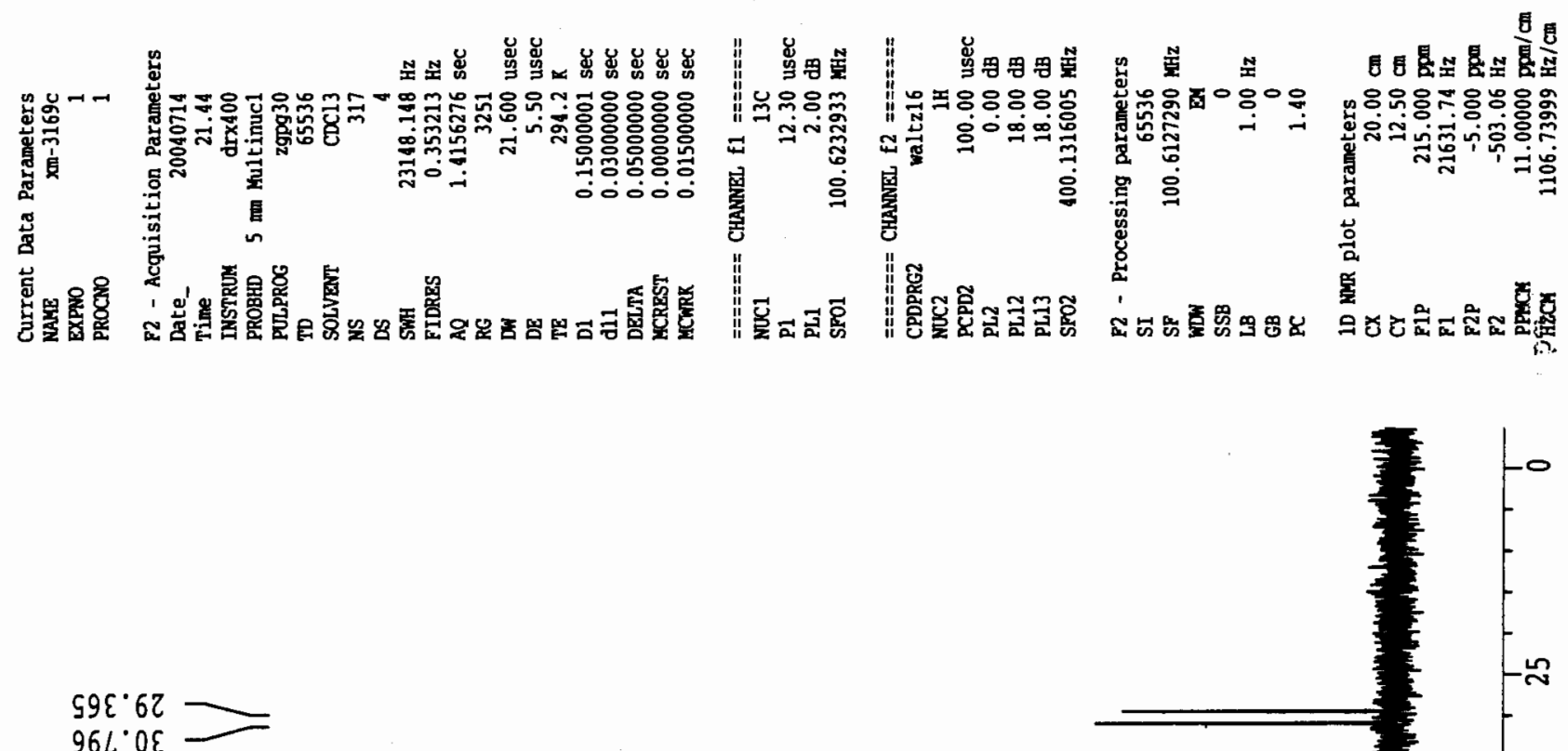

$69 \varepsilon^{\circ} \varsigma 9$

$\nabla 2 \nabla^{\circ} \angle 9$

ZTT'LL

OEF $L L$

$8 T L^{\circ} L L$

$67 \varepsilon^{\circ}$ TOT-
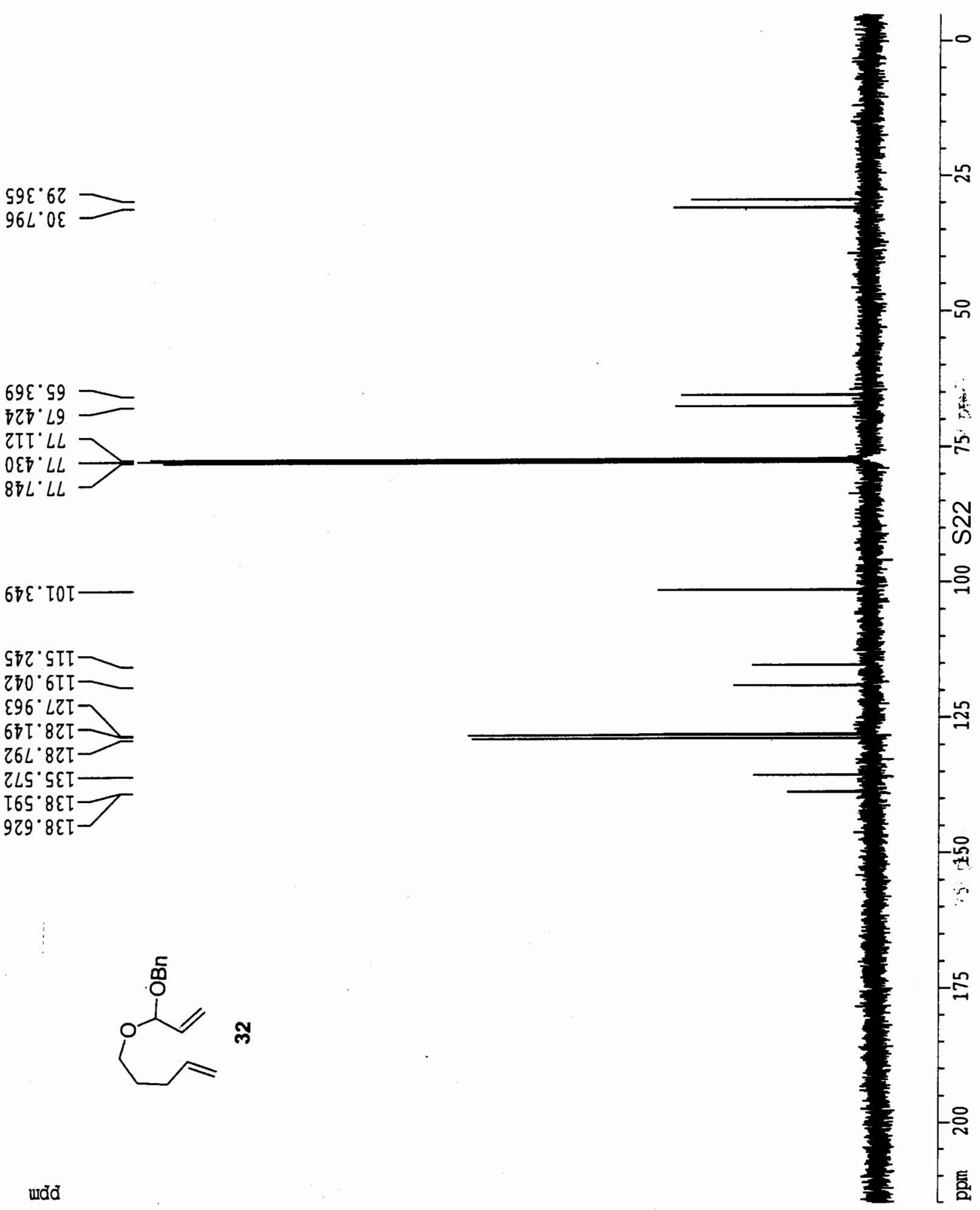

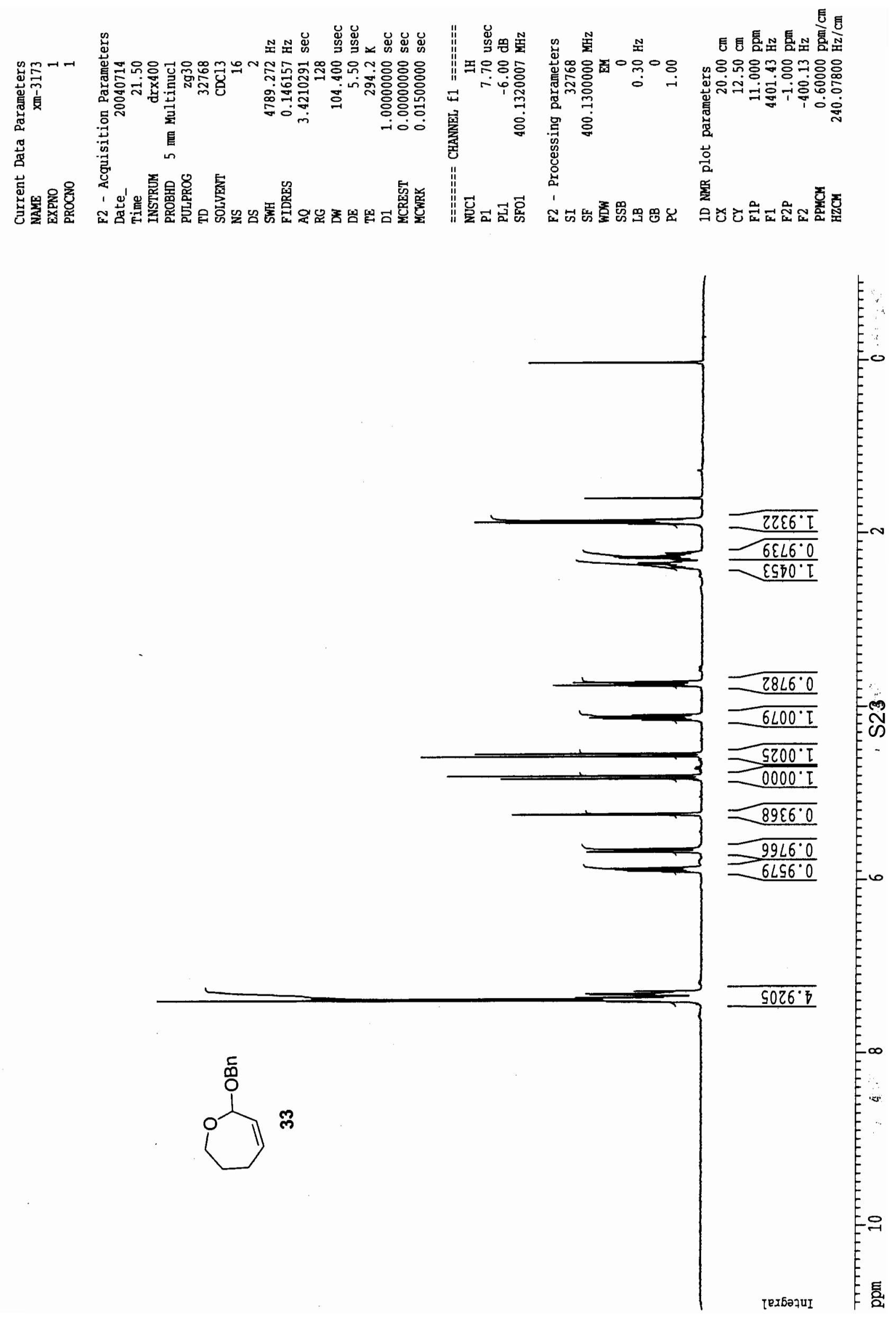

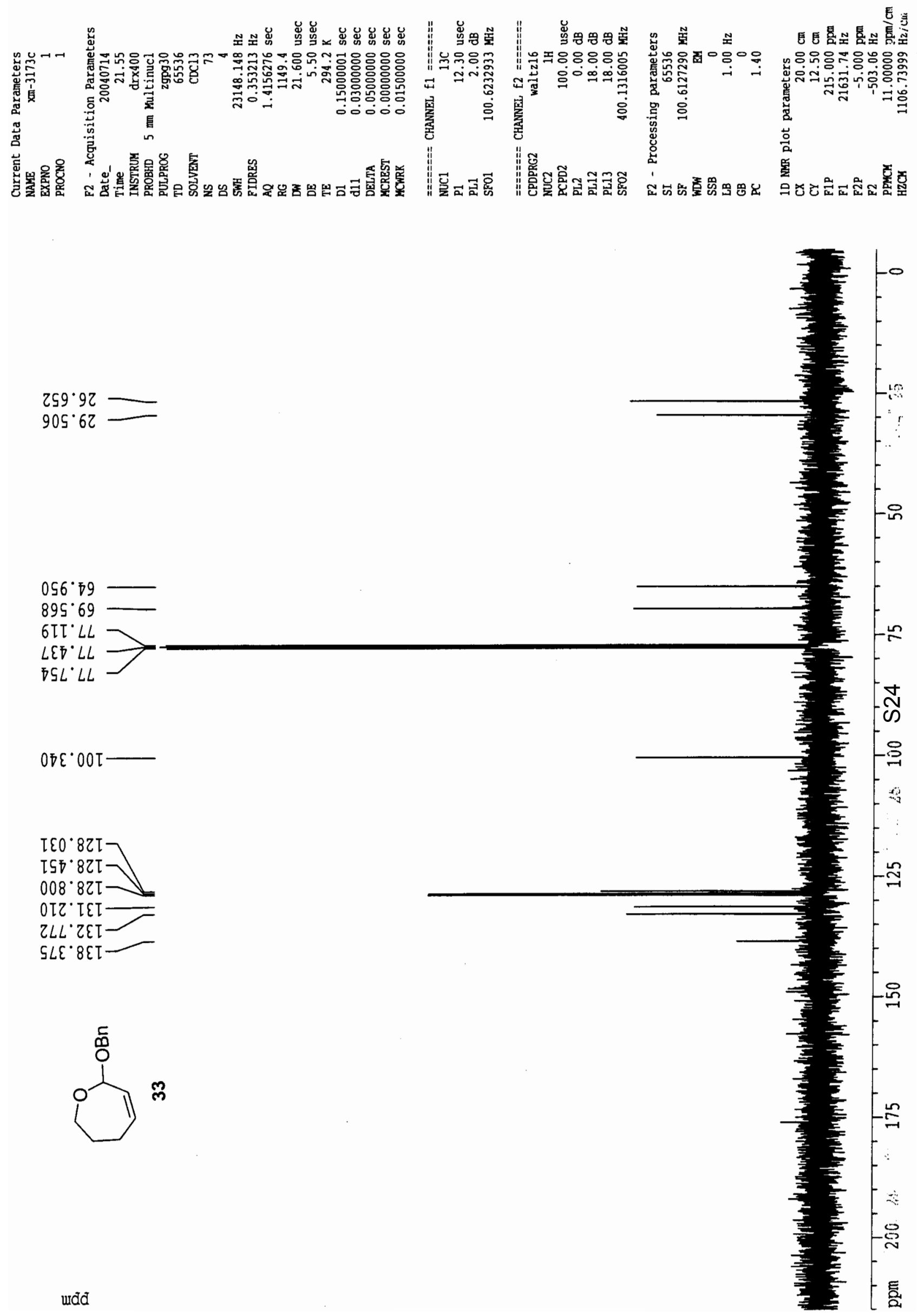

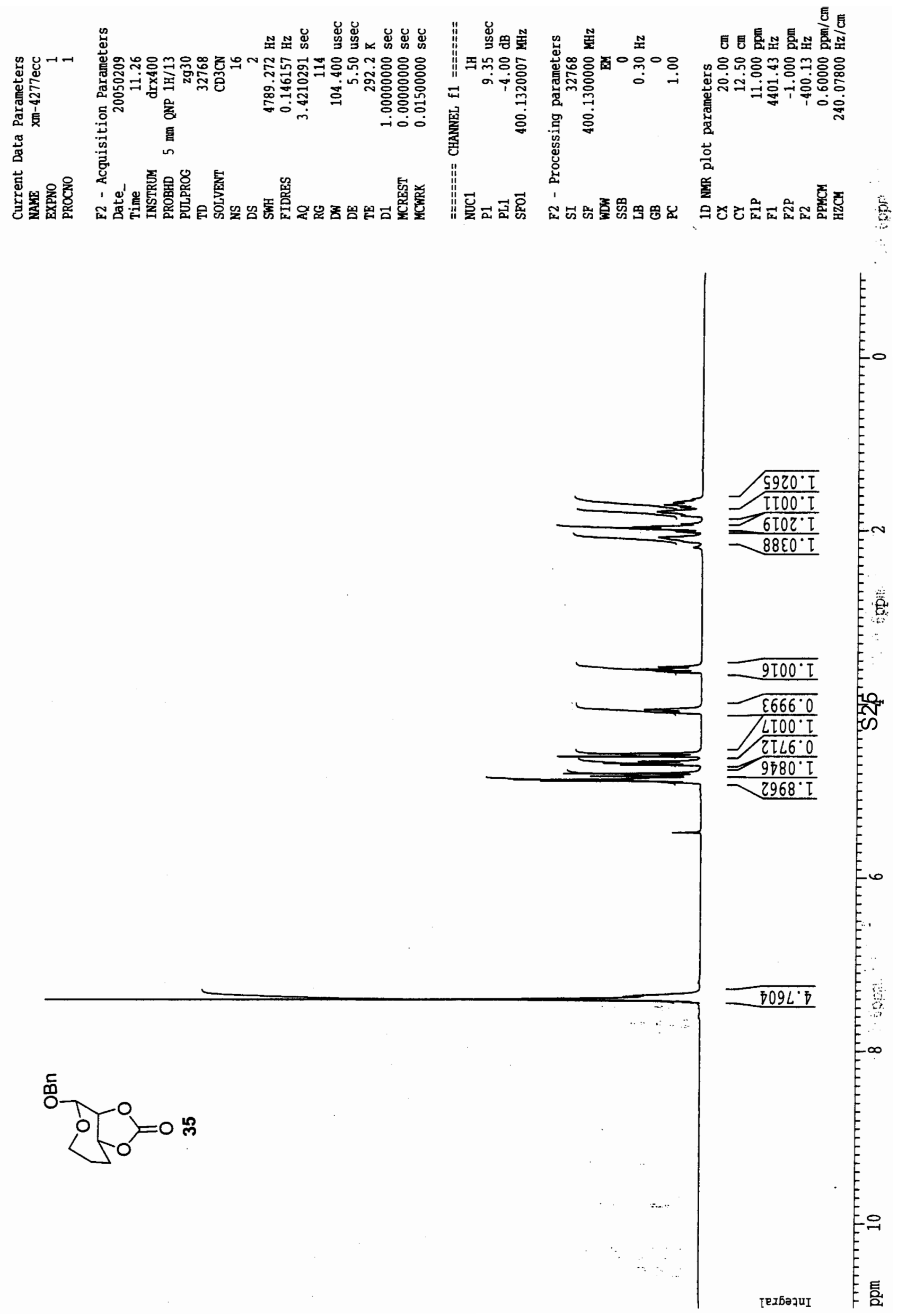

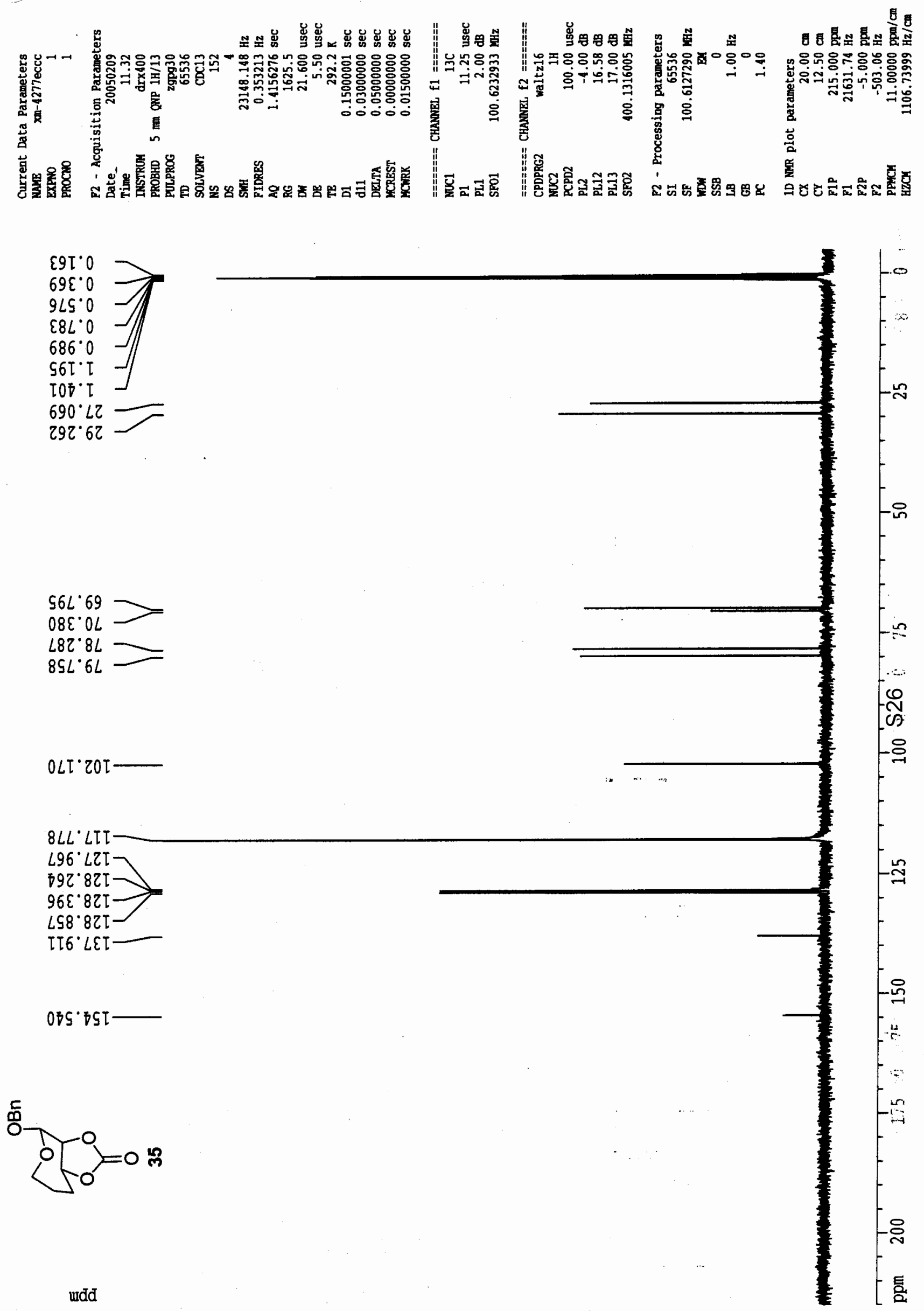

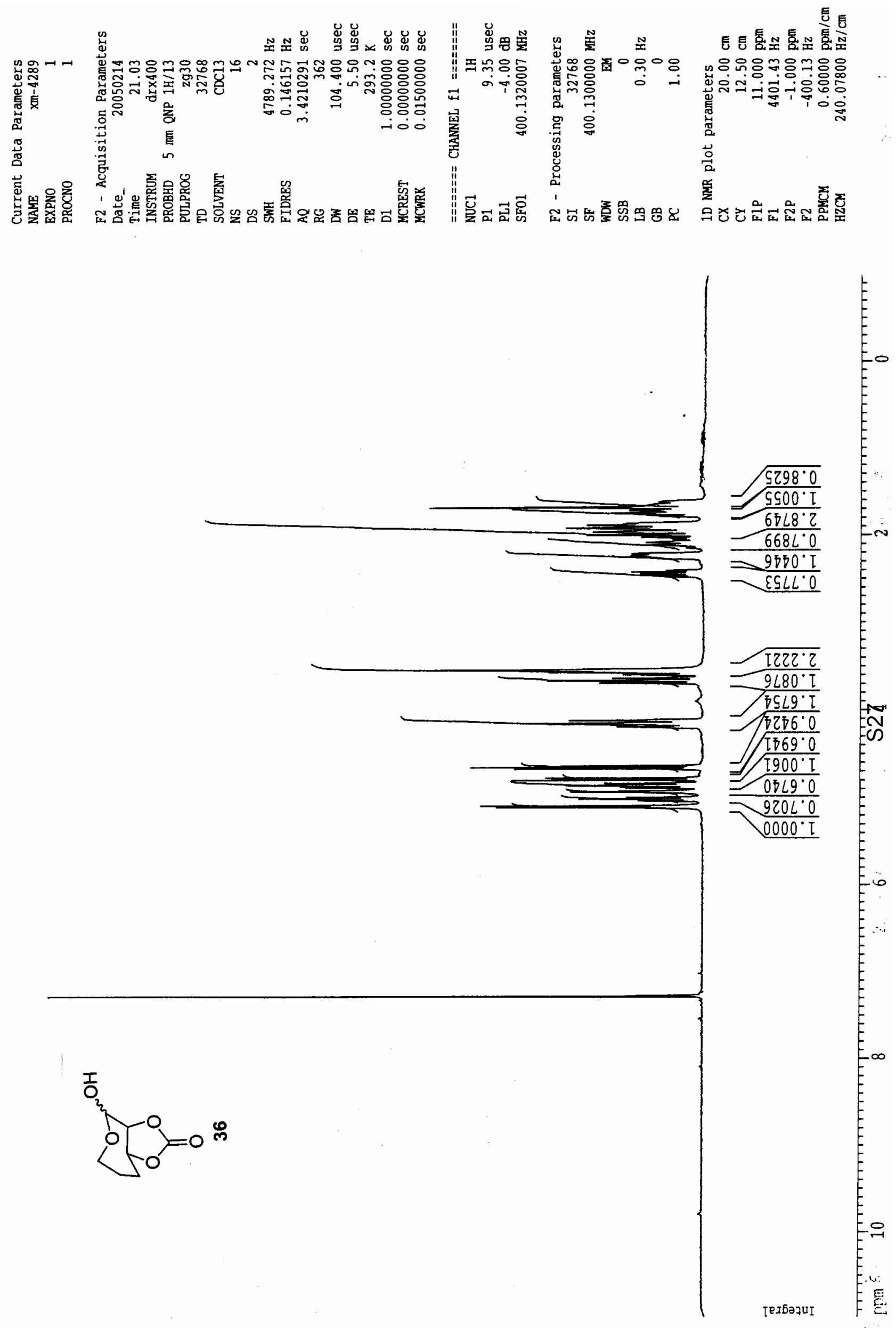

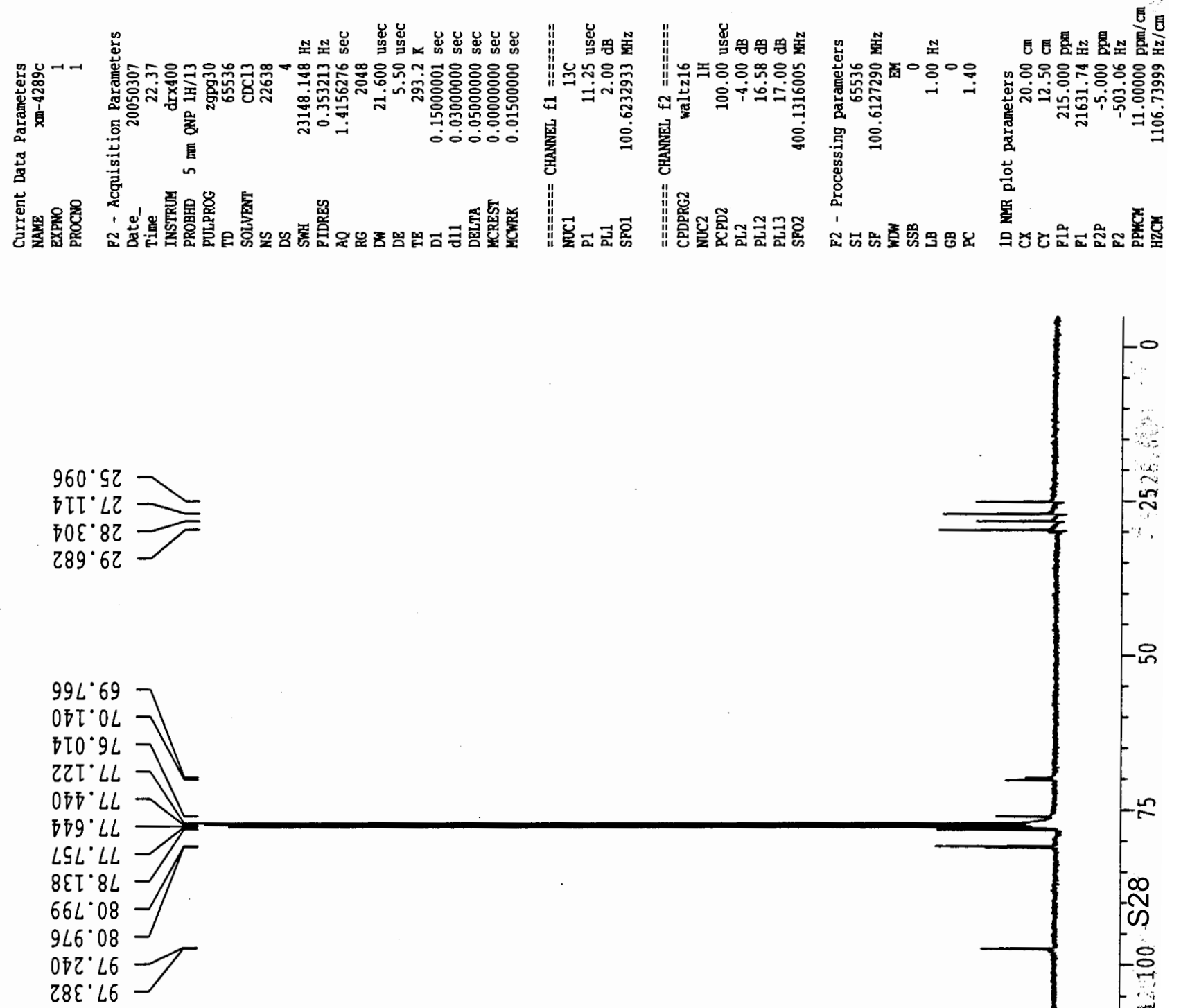

ซร์'ซรI -

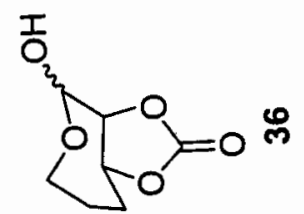



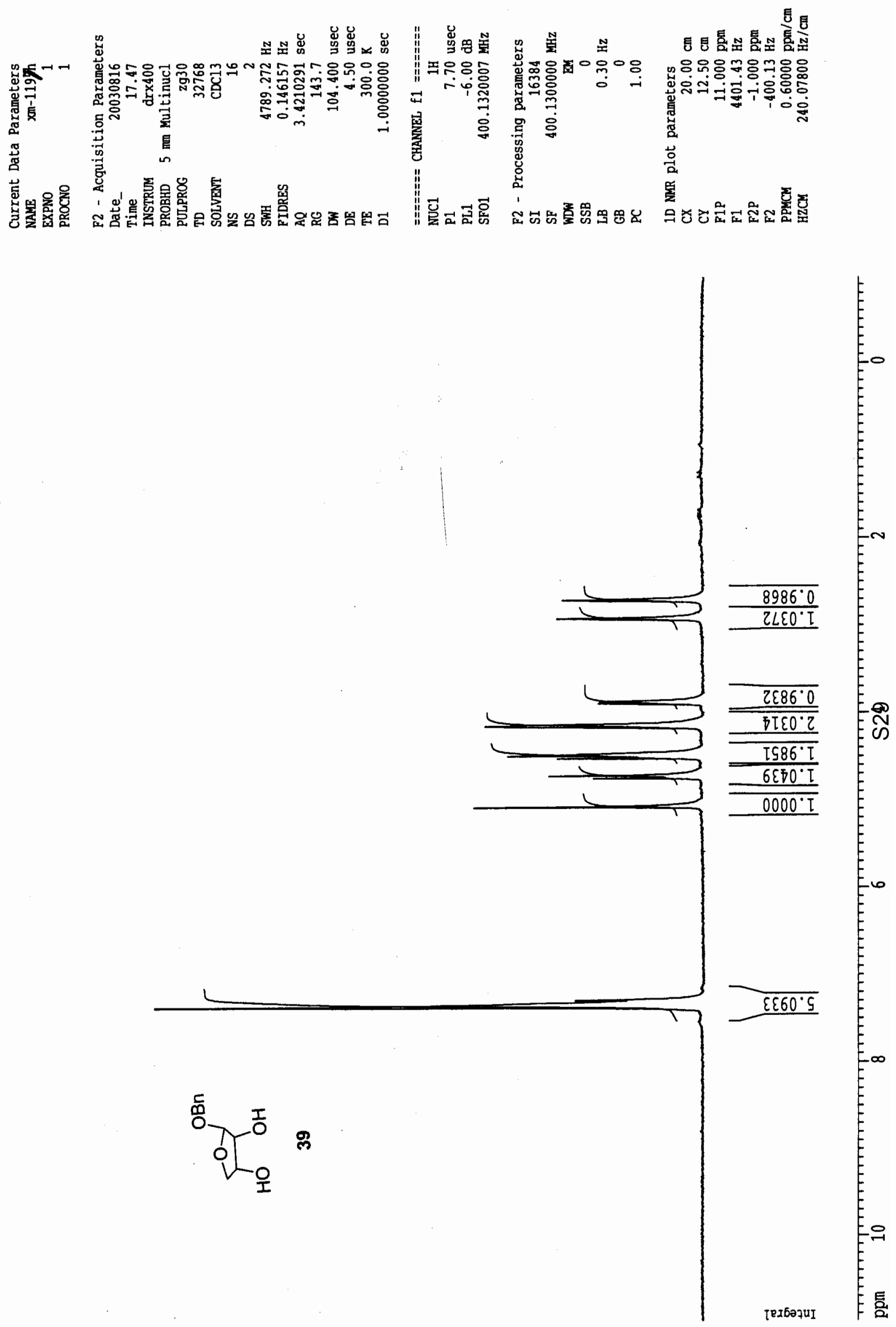

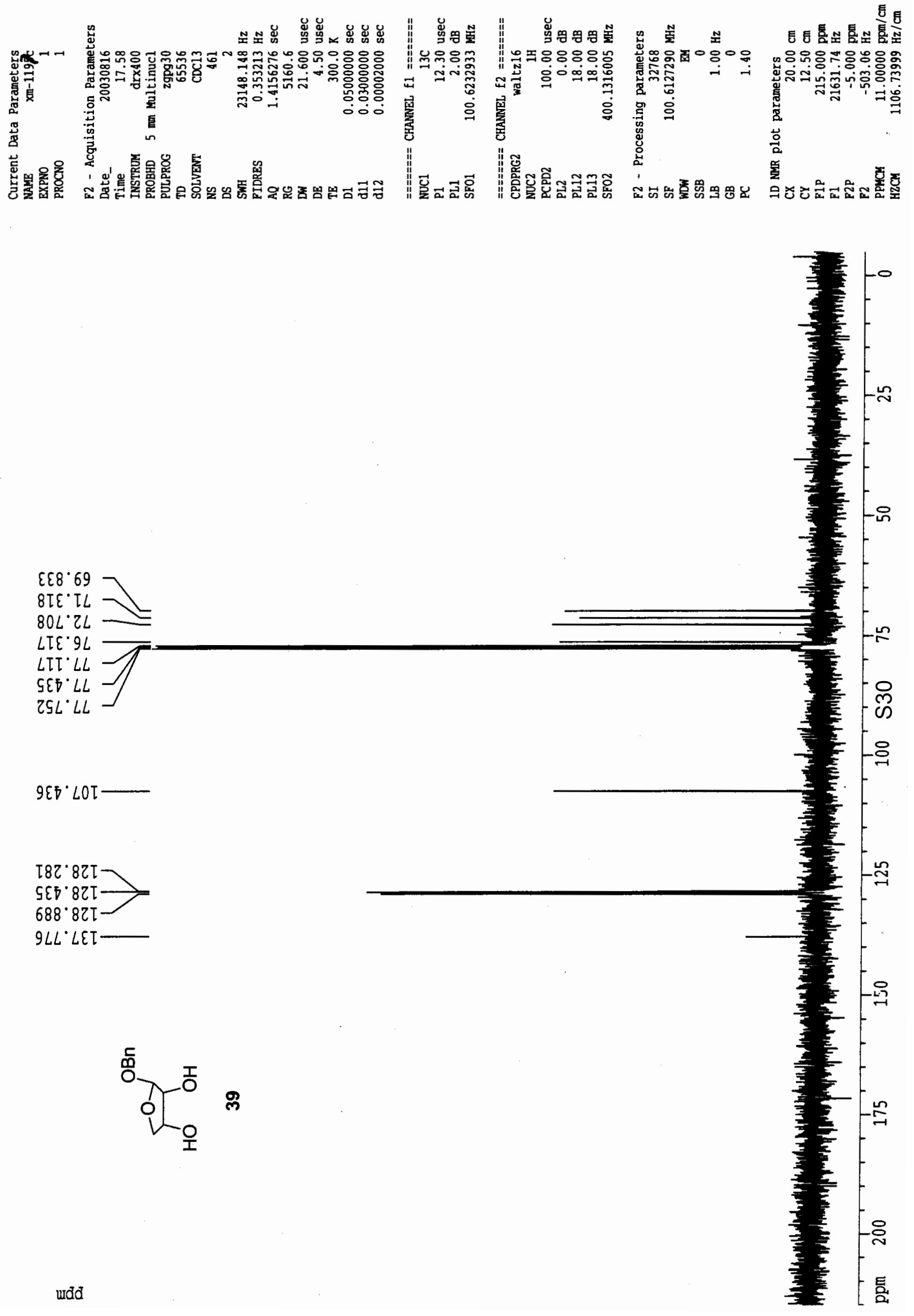

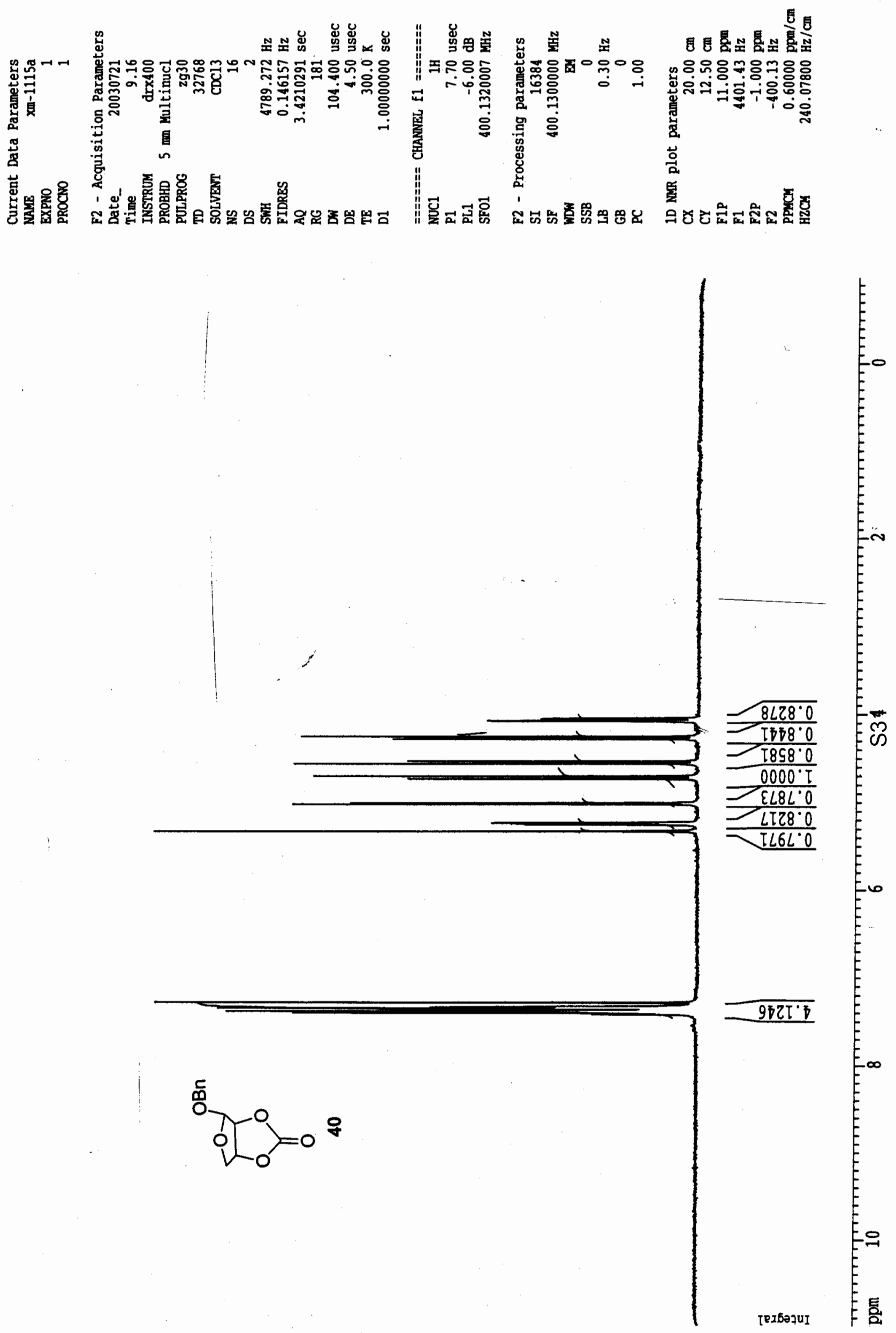

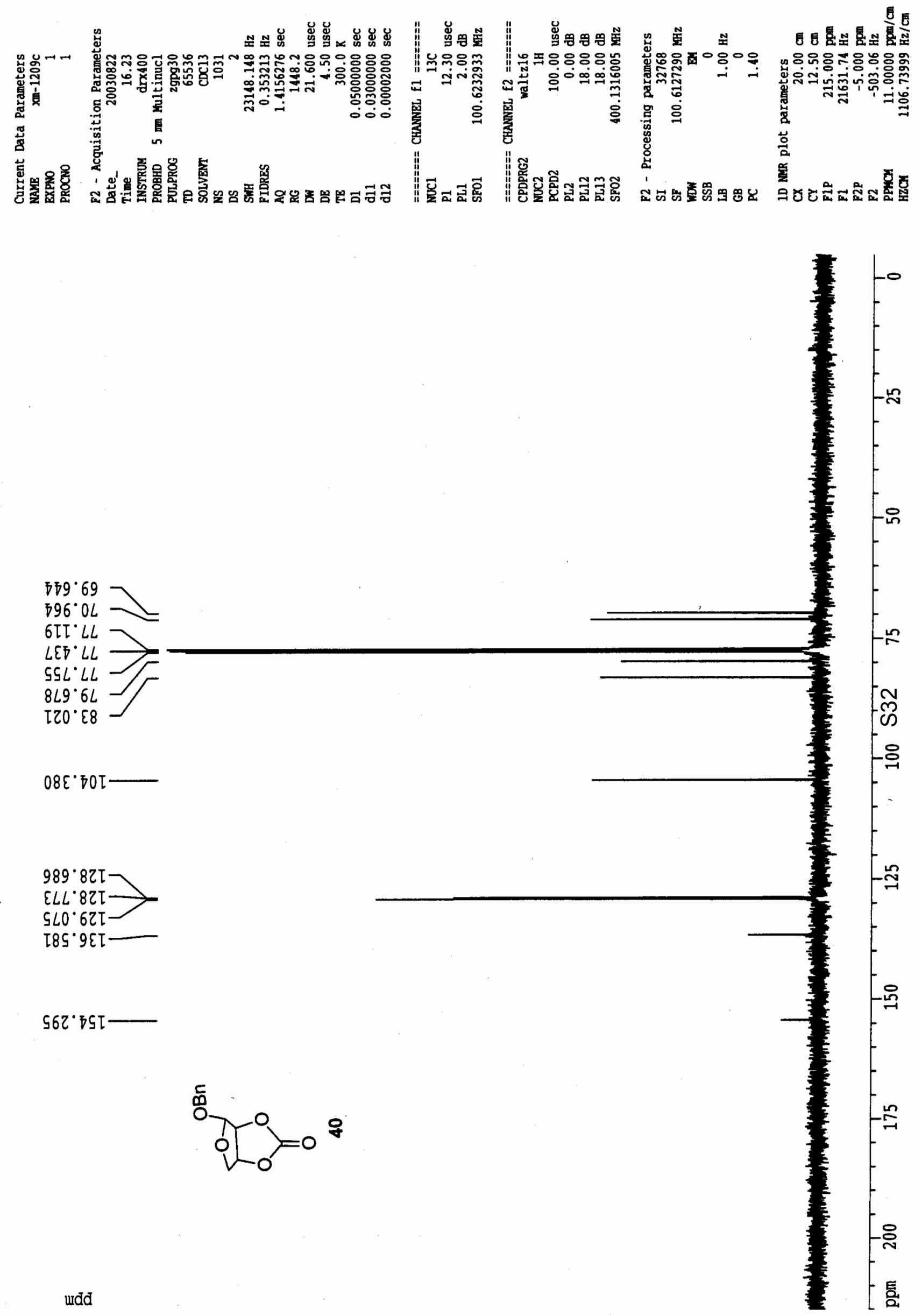

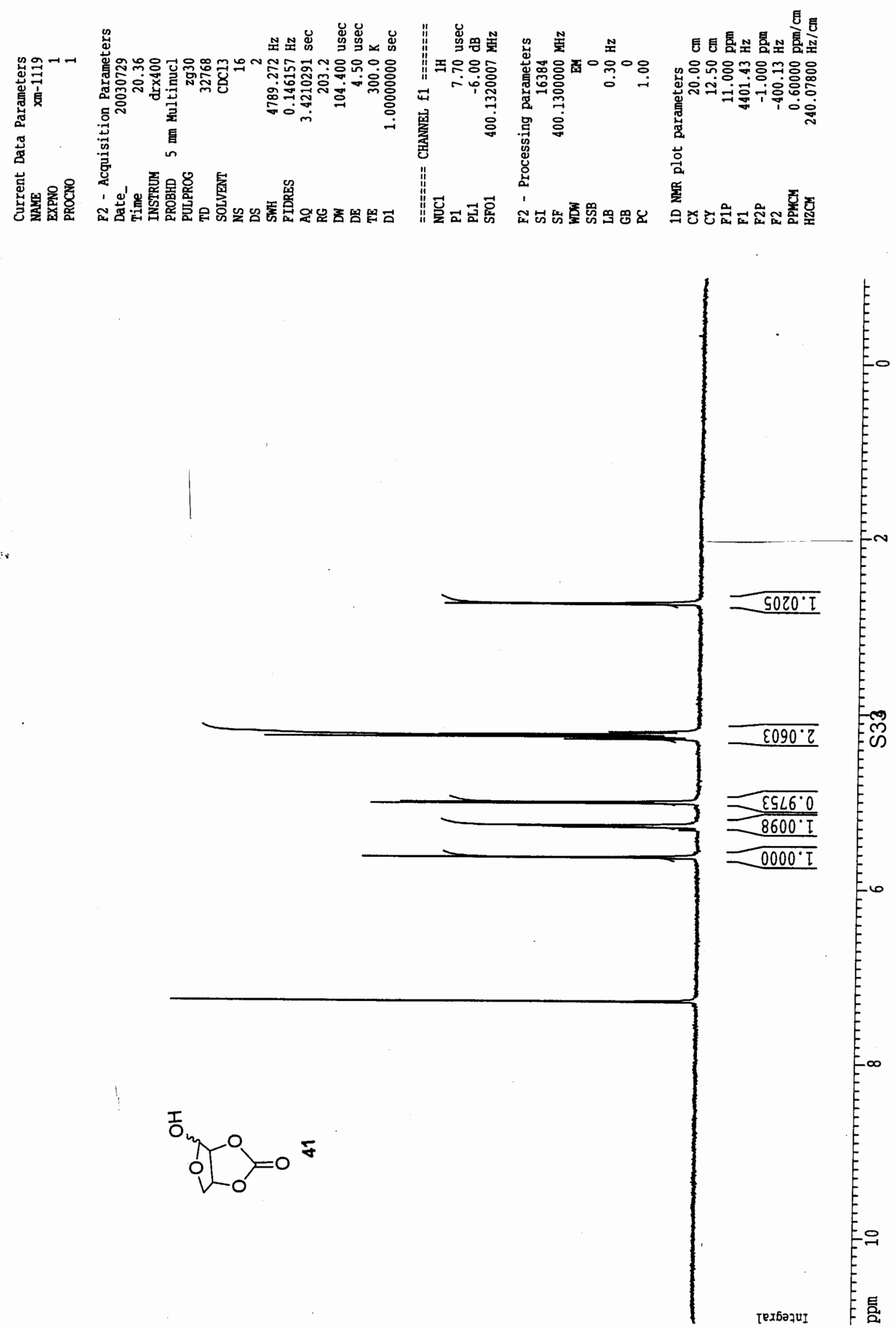

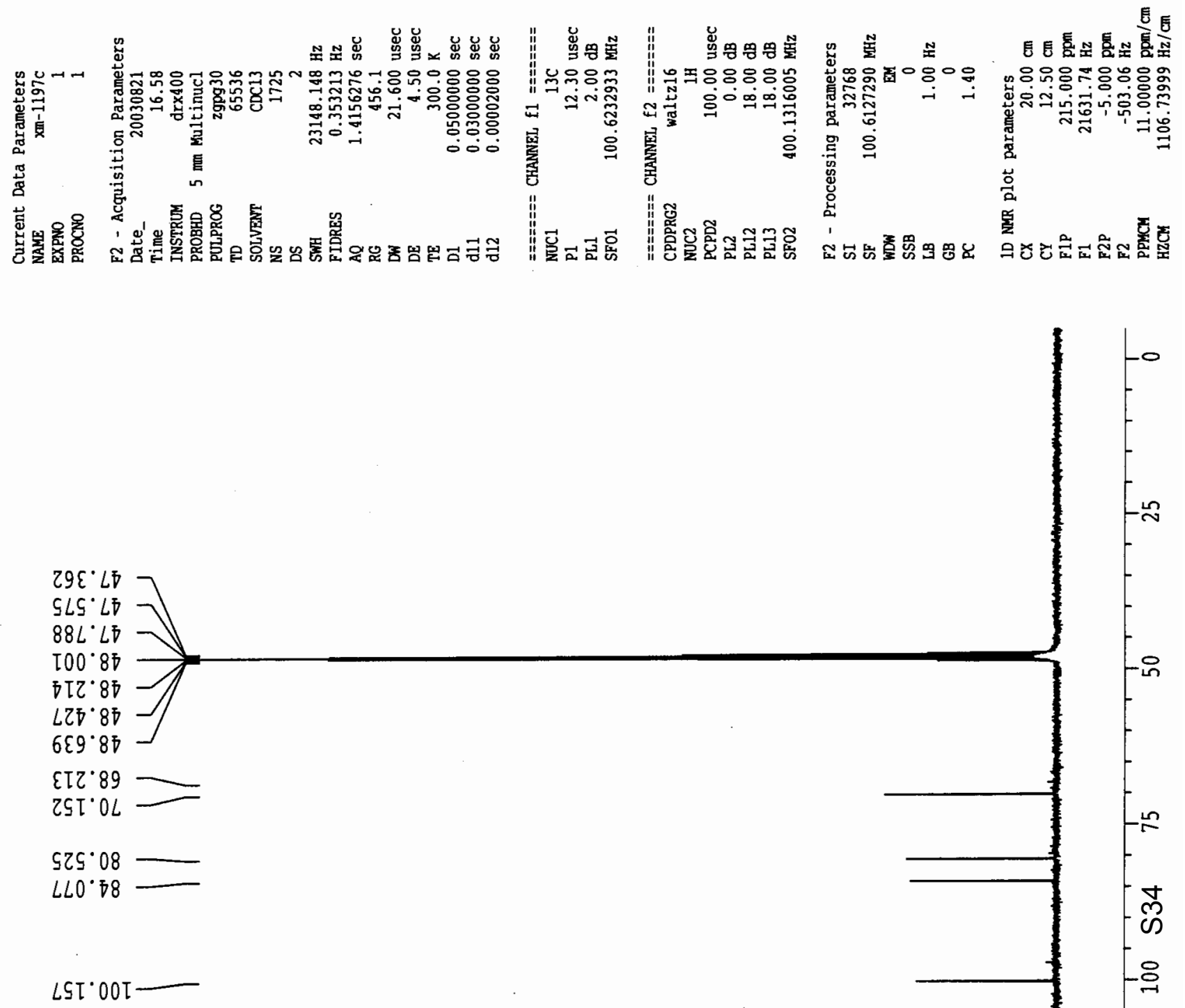

OLE ऽST-<smiles>[CH-]=C[C@@H]1OC2OC(=O)OC21</smiles> 

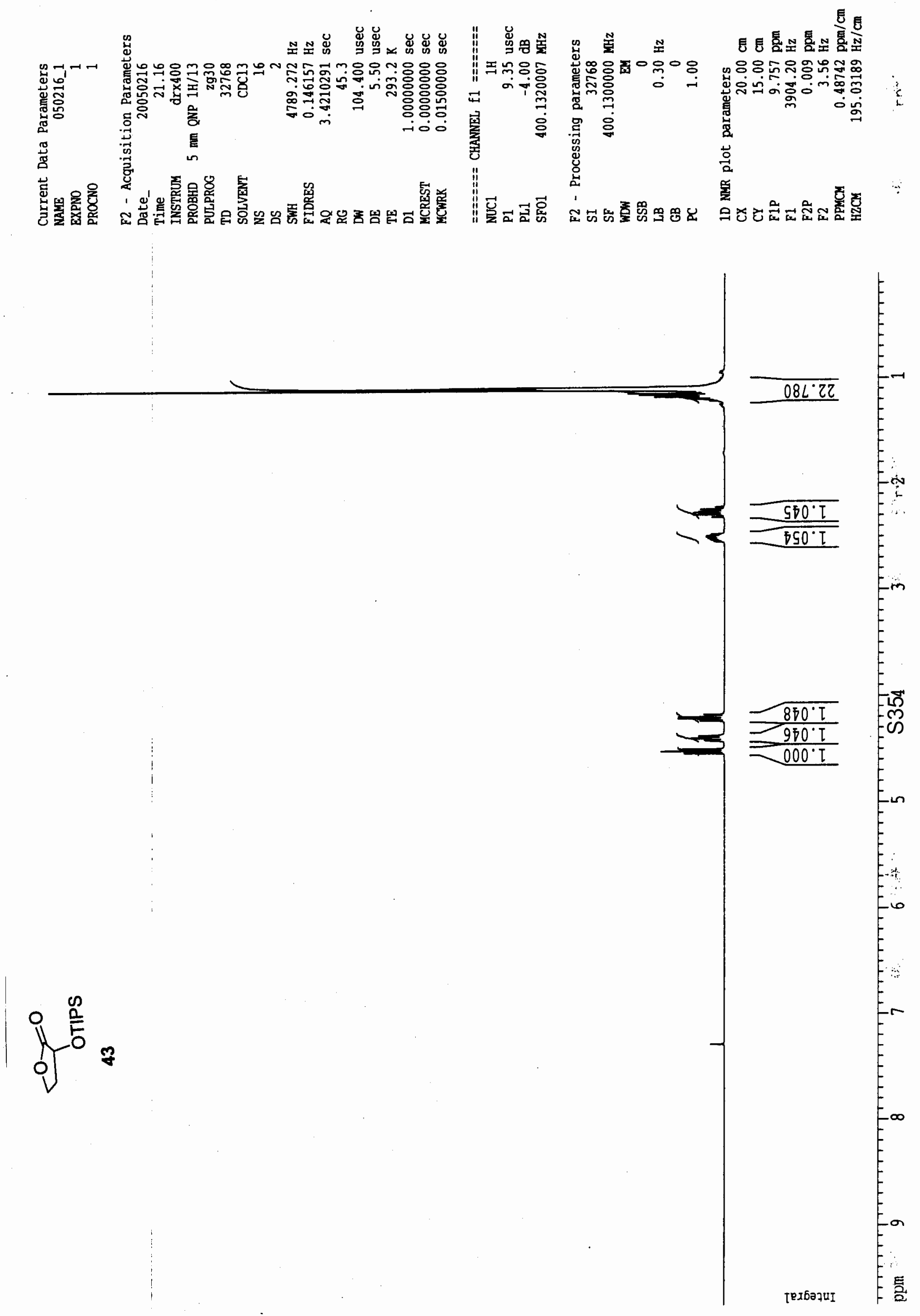

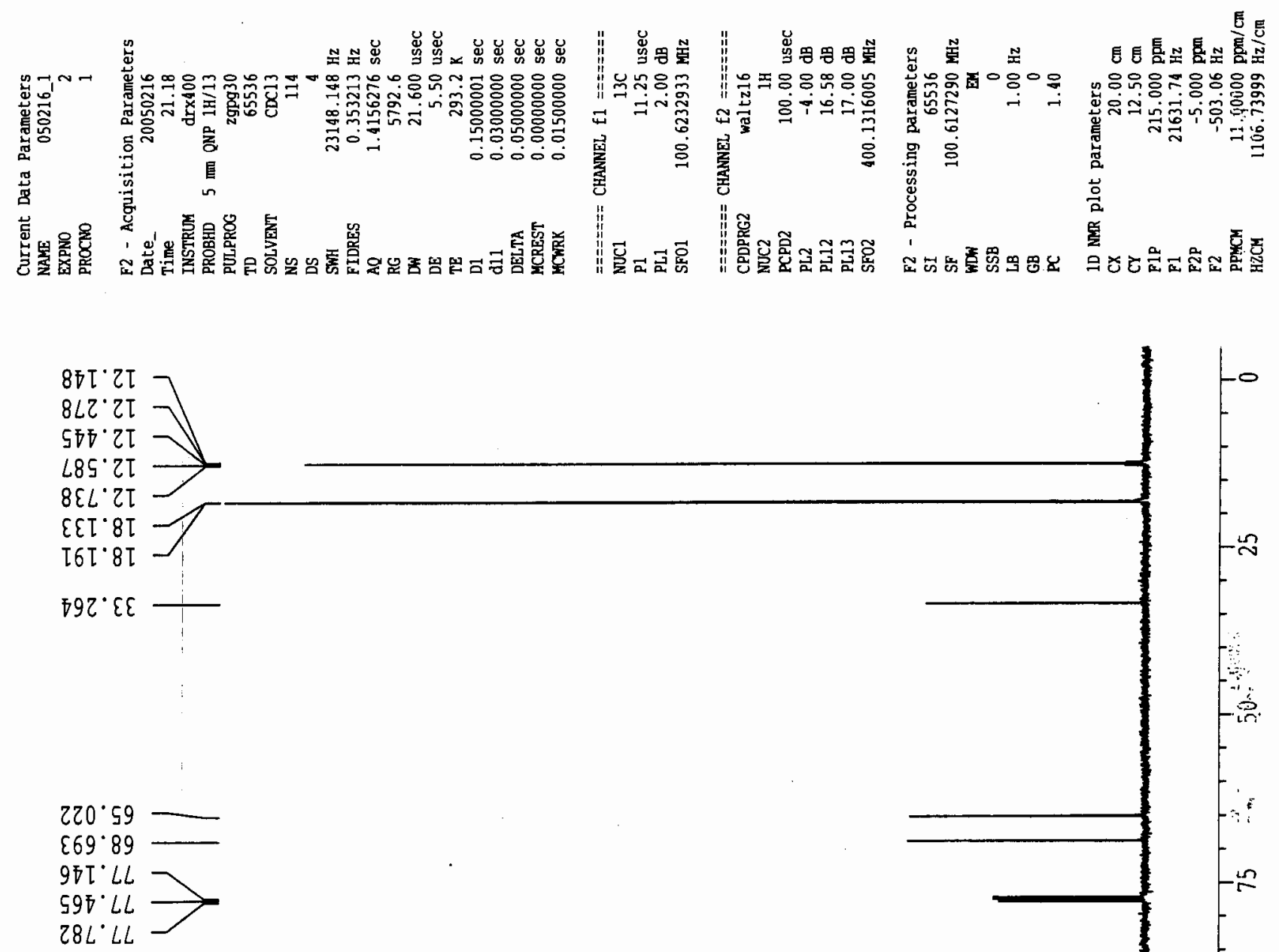

IZI' $9 L T$

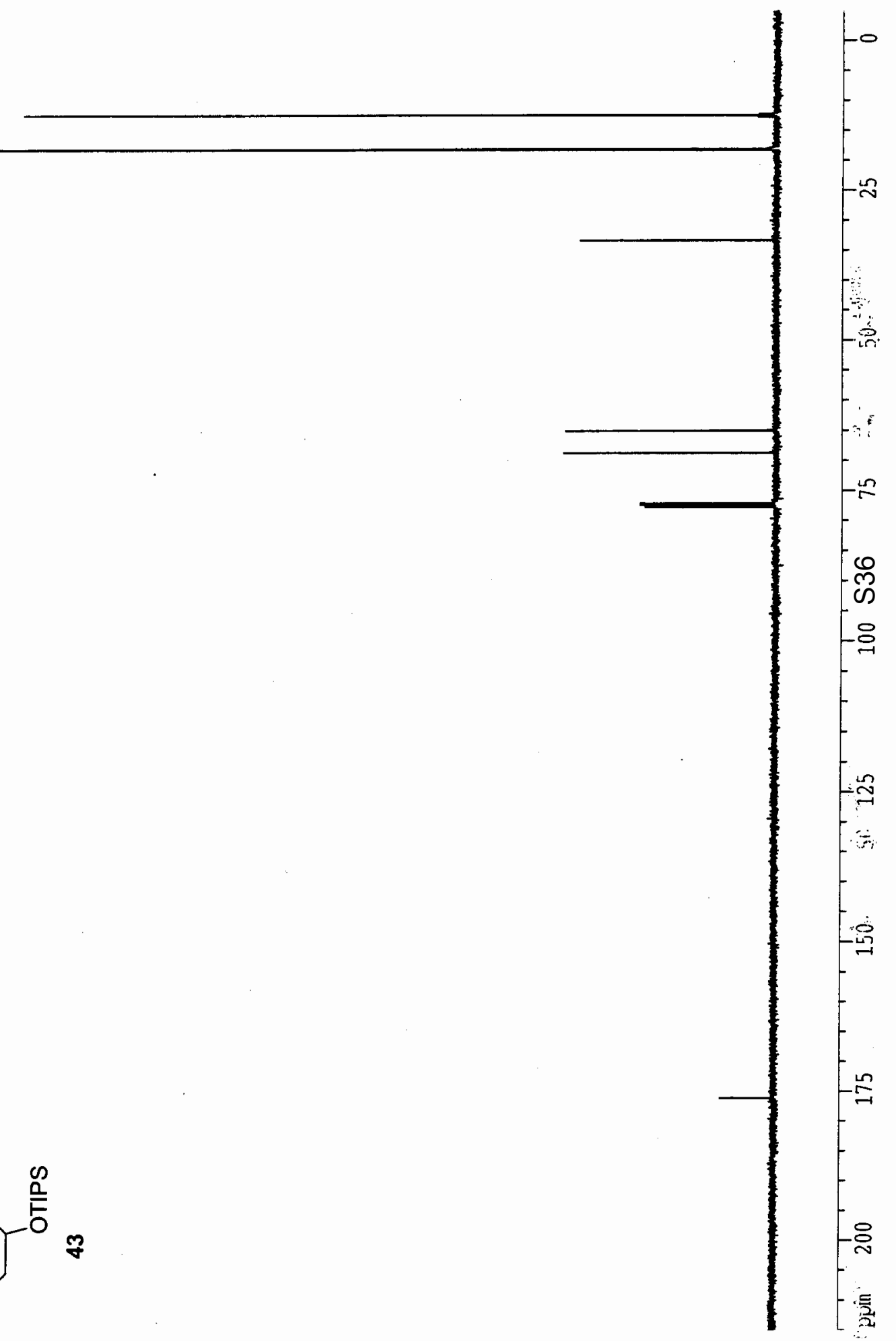



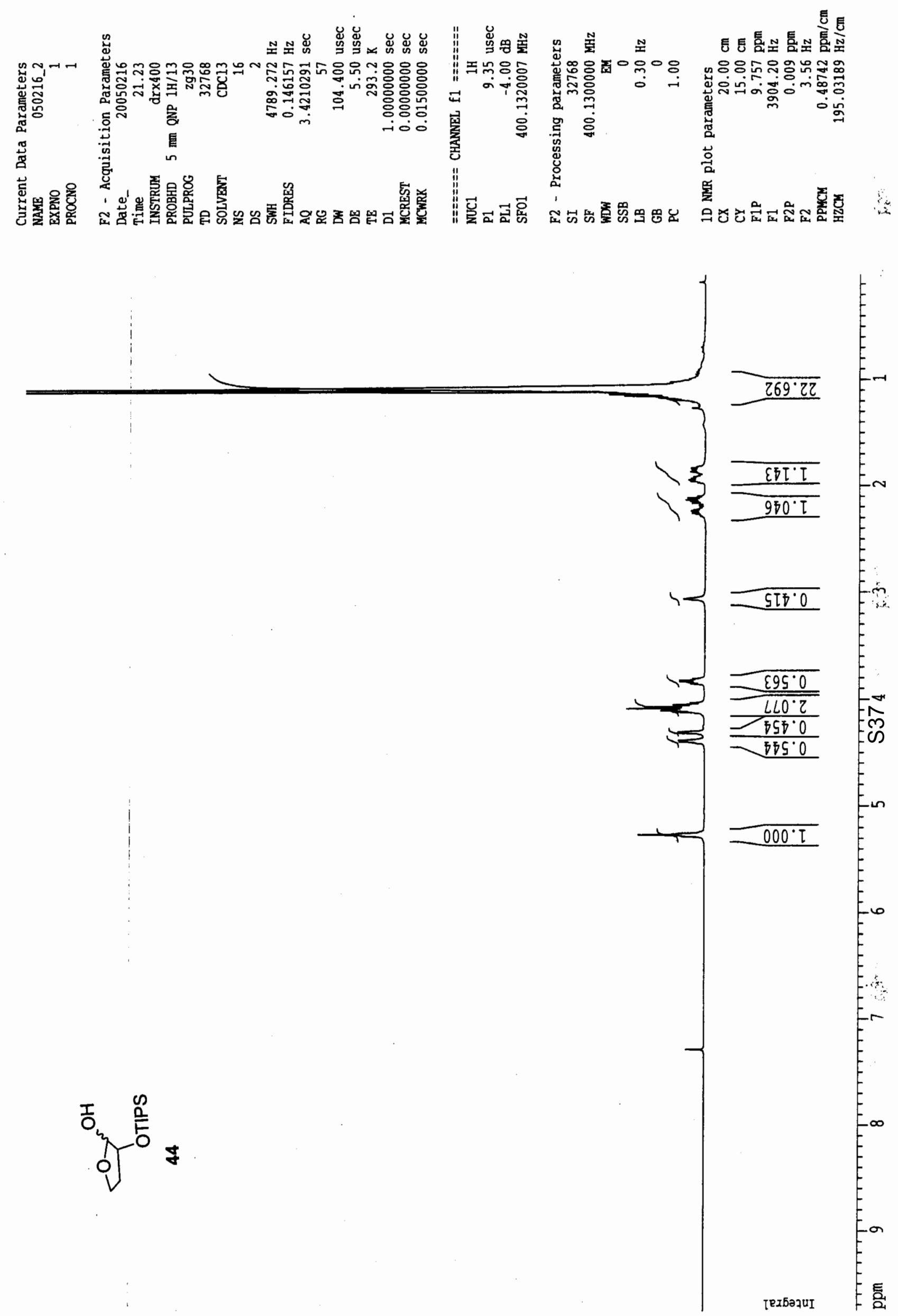

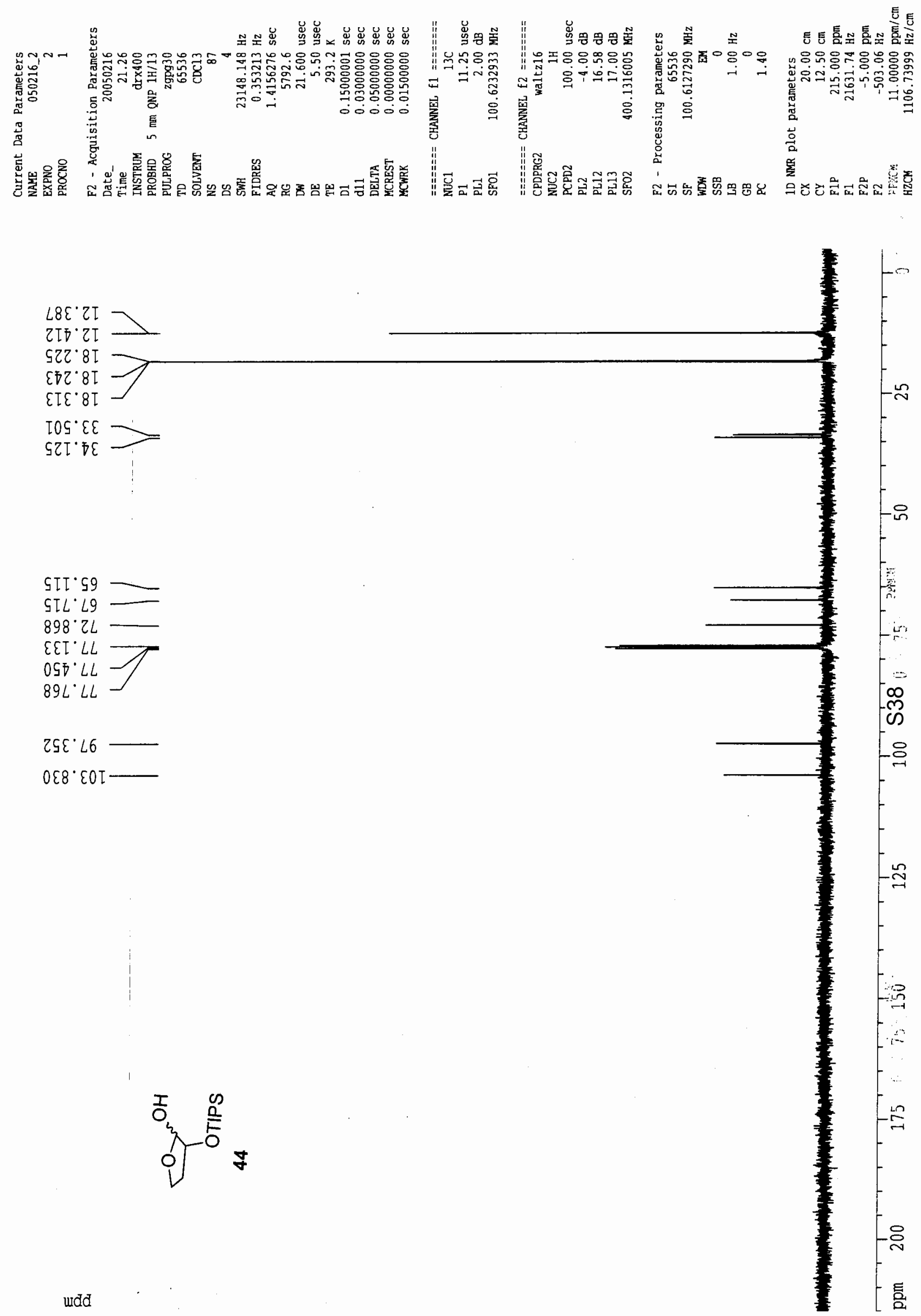

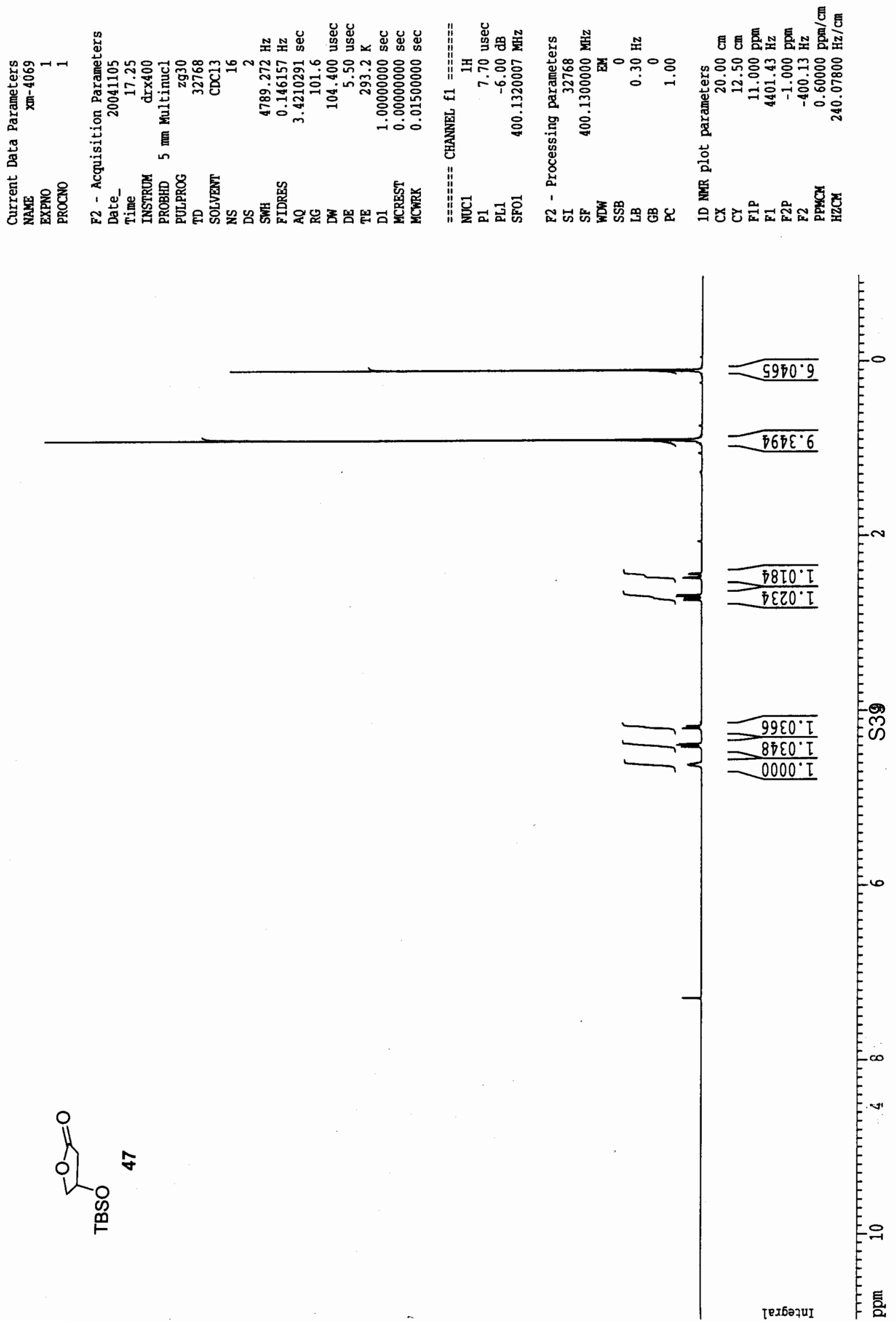

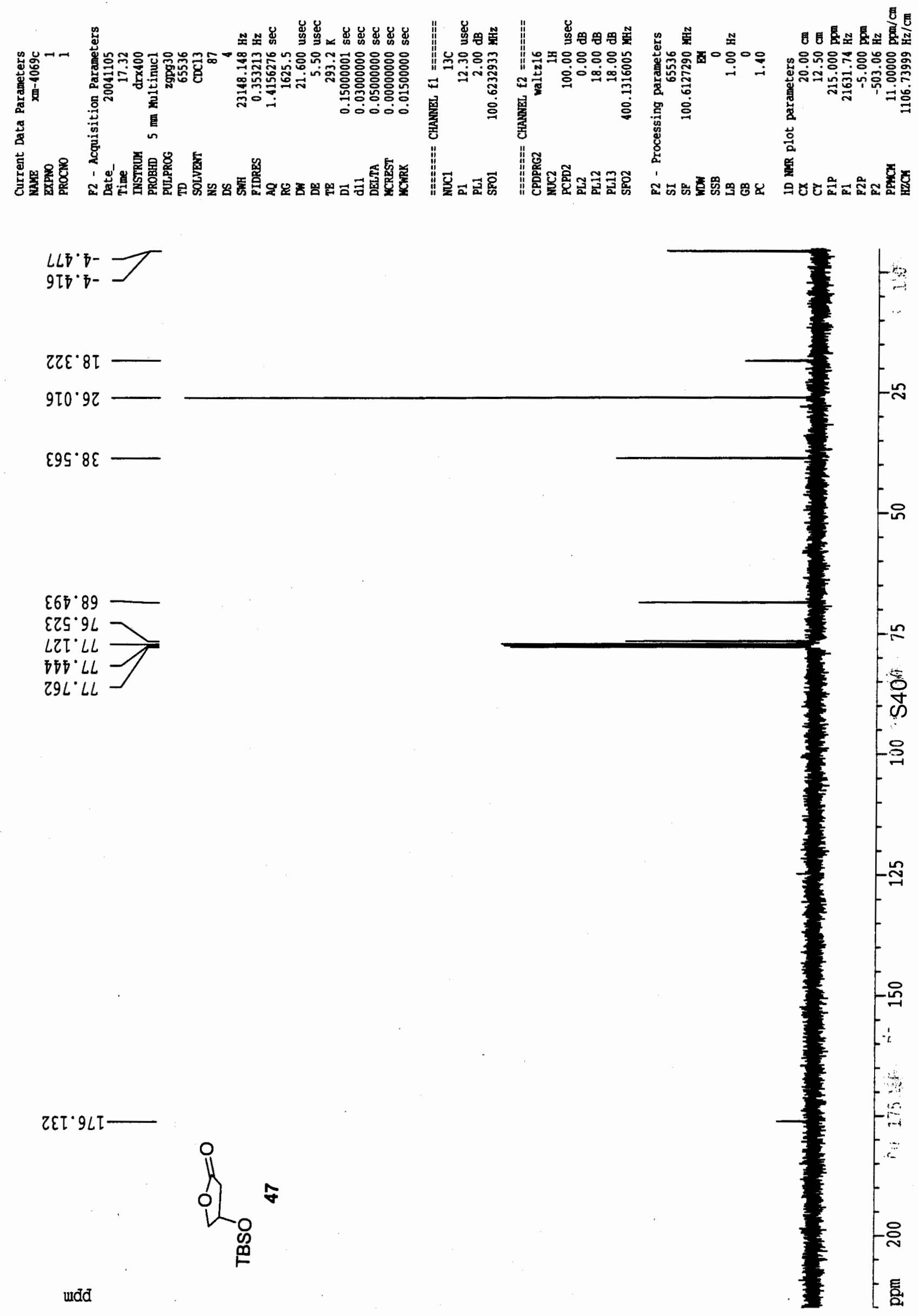

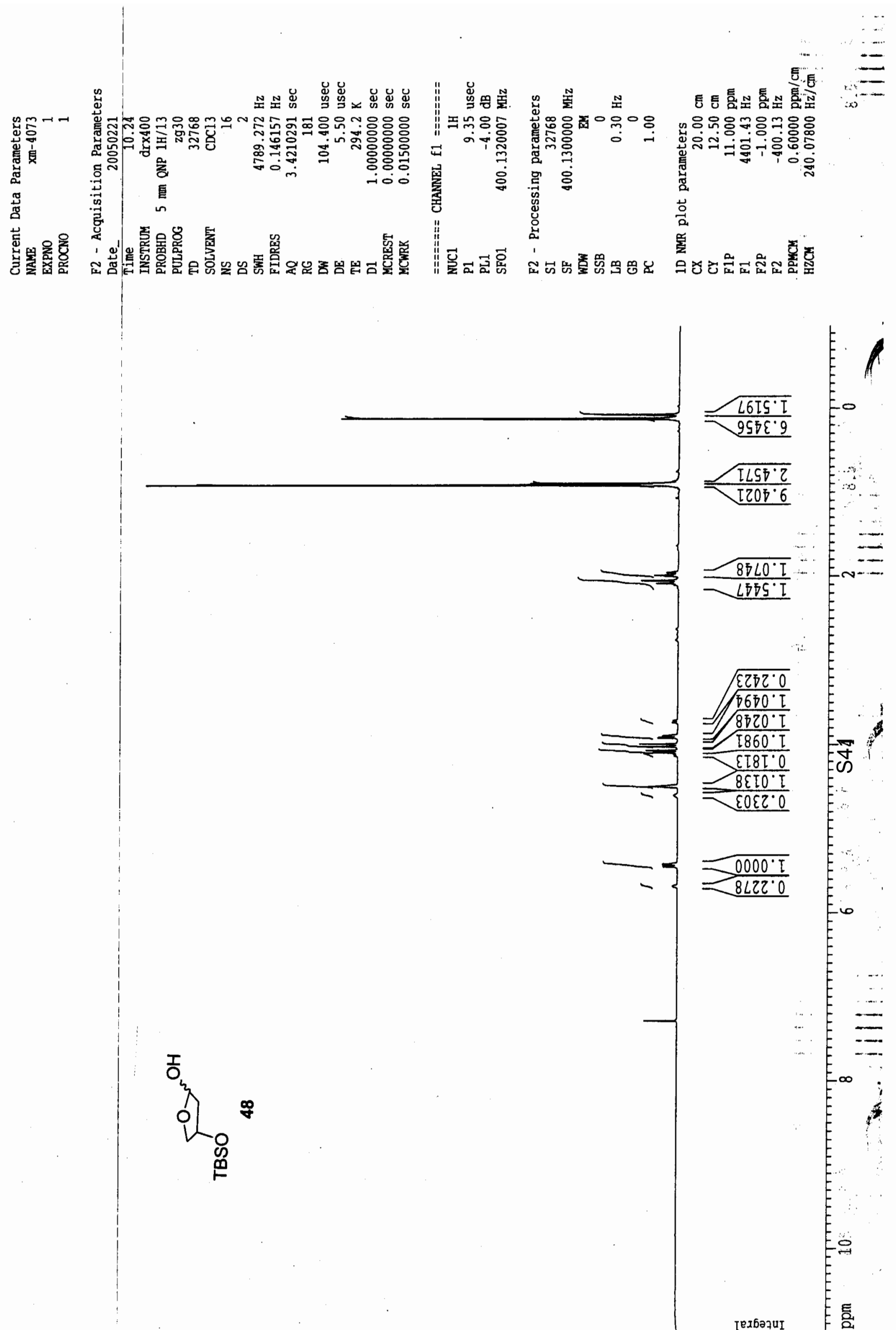

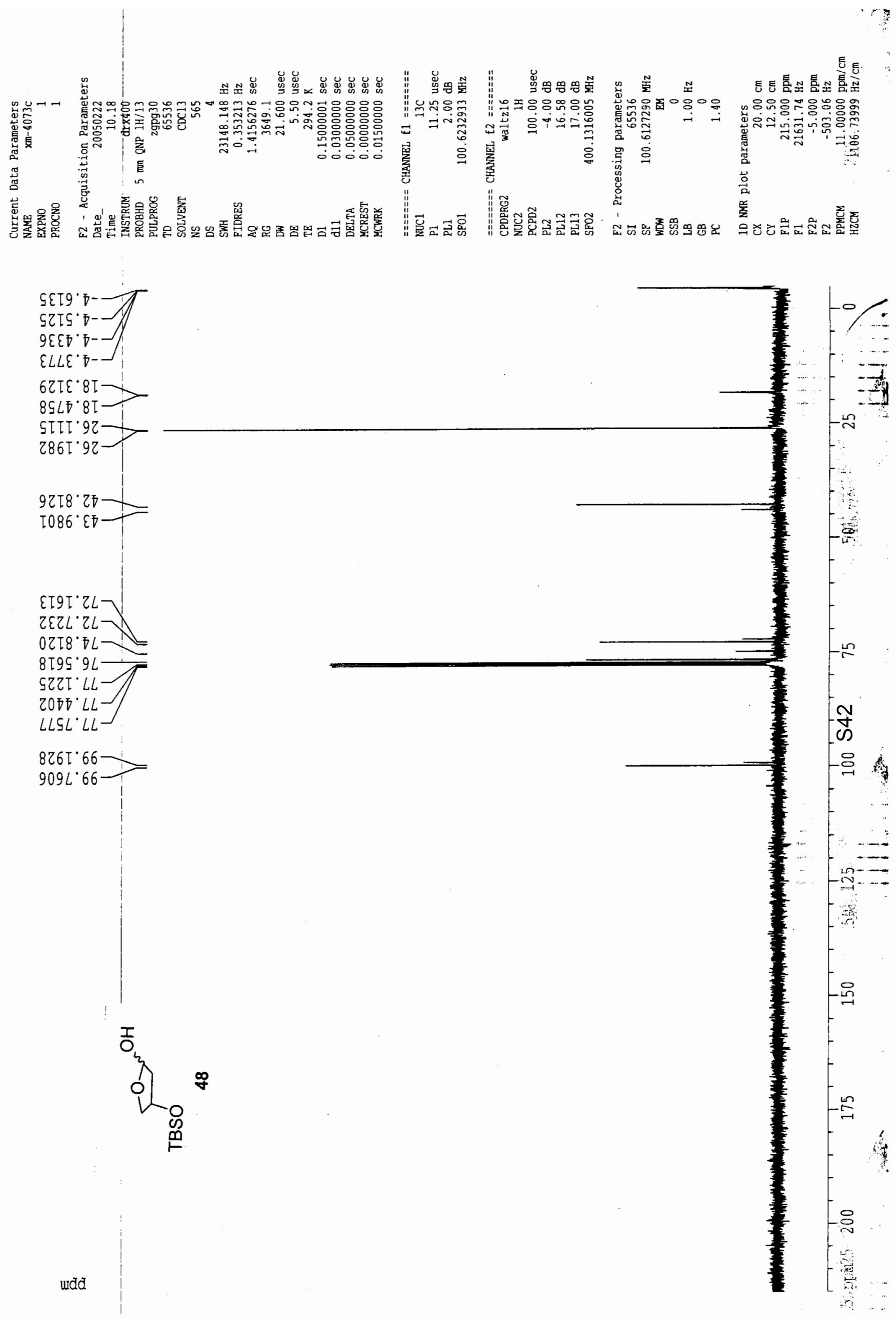